\title{
Ecophysiology of tea
}

\author{
W.A. Janendra M. De Costa ${ }^{1 *}$, A. Janaki Mohotti ${ }^{2}$ and Madawala A. Wijeratne ${ }^{3}$ \\ ${ }^{1}$ Department of Crop Science, Faculty of Agriculture, University of Peradeniya, Peradeniya 20400, Sri Lanka. ${ }^{2}$ Head, Plant Physiology \\ Division, Tea Research Institute, St. Coomb's Estate, Talawakelle, Sri Lanka. ${ }^{3}$ Senior Research Officer, Tea Research Institute, Low- \\ Country Research Station, Ratnapura, Sri Lanka.*Corresponding author: janendrad@yahoo.com
}

Received: 11 October 2007; Accepted: 31 October 2007

Tea [Camellia sinensis (L.) O. Kuntze] is one of the most important beverage crops in the world. The major tea-growing regions of the world are South-East Asia and Eastern Africa where it is grown across a wide range of altitudes up to 2200 $\mathrm{m}$ a.s.1.. This paper reviews the key physiological processes responsible for yield determination of tea and discusses how these processes are influenced by genotypic and environmental factors. Yield formation of tea is discussed in terms of assimilate supply through photosynthesis and formation of harvestable sinks (i.e. shoots). The photosynthetic apparatus and partial processes (i.e. light capture, electron transport and carboxylation) of tea show specific adaptations to shade. Consequently, maximum light-saturated photosynthetic rates of tea are below the average for $\mathrm{C}_{3}$ plants and photoinhibition occurs at high light intensities. These processes restrict the source capacity of tea. Tea yields are sink-limited as well because shoots are harvested before their maximum biomass is reached in order to maintain quality characters of made tea. In the absence of water deficits, rates of shoot initiation and extension are determined by air temperature and saturation vapour pressure deficit, with the former having positive and the latter having negative relationships with the above rates. During dry periods, when the soil water deficit exceeds a genotypically- and environmentally-determined threshold, rates of shoot initiation and extension are reduced with decreasing shoot water potential. Tea yields respond significantly to irrigation, a promising option to increase productivity during dry periods, which are experienced in many tea-growing regions.

Key words: climate change, photoinhibition, photosynthesis, shoot growth, temperature, vapour pressure deficit, water potential

Ecofisiologia do chá: O chá [Camellia sinensis (L.) O. Kuntze] é uma das mais importantes culturas para a produção de bebidas no mundo. As principais regiões de cultivo dessa espécie se concentram no sudeste da Ásia e na África oriental, onde é cultivado numa ampla faixa de altitudes, até $2200 \mathrm{~m}$ acima do nível do mar. Neste artigo, revisam-se processos fisiológicos centrais determinantes da produção do chá e se discutem como esses processos são influenciados por fatores genotípicos e ambientes. A produção do chá é discutida em termos de suprimento de assimilados provenientes da fotossíntese e formação de drenos (ramos) removidos na colheita. A maquinaria fotossintética e processos parciais (i.e. captura de luz, transporte de elétrons e carboxilação) da fotossíntese, em plantas de chá, exibem adaptações à sombra. Conseqüentemente, as taxas máximas de fotossíntese saturadas à luz são inferiores às da media de plantas $\mathrm{C}_{3}$, observando-se também fotoinibição sob altas irradiâncias. Esses processos restringem a capacidade da fonte em plantas de chá. A produção do chá é limitada pelo dreno conquanto os ramos são colhidos antes de atingirem sua biomassa máxima, o que é feito com o intuito de se preservarem os caracteres de qualidade da bebida processada. $\mathrm{Na}$ ausência de déficit hídrico, as taxas de iniciação e de extensão de ramos são determinadas pela temperatura do ar e pelo déficit de pressão de vapor, tendo a temperatura um efeito positivo, e o segundo fator afetando negativamente aquelas taxas. Em períodos de estiagem, quando o déficit hídrico no solo atinge um limiar, determinado genotípica e ambientalmente, as taxas de iniciação e de extensão dos ramos são reduzidas com o decréscimo do potencial

${ }^{\dagger}$ All authors have contributed equally to this article

Braz. J. Plant Physiol., 19(4):299-332, 2007 
hídrico desses ramos. A produção do chá responde significativamente à irrigação, uma opção promissora para aumentar a produtividade durante períodos secos, que são freqüentes em muitas regiões onde essa espécie é cultivada.

Palavras-chave: crescimento de ramos, déficit de pressão de vapor, fotoinibição, fotossíntese, mudança climática, potencial hídrico, temperatura

\section{INTRODUCTION}

Ecological range: Tea [Camellia sinensis (L.) O. Kuntze] is one of the major beverage crops in the world. Tender shoots of tea consisting of two or three leaves and a bud are harvested periodically to produce either 'black' (i.e. withered and fermented) or 'green' (i.e. withered but unfermented) tea. South-East Asia (i.e. India and Sri Lanka) and Eastern- and Southern Africa (i.e. Kenya, Malawi, Tanzania, Uganda and Mozambique) are the major producers of black tea, while China and Japan are the major producers of green tea. Ecophysiology of the commercially-grown tea plant is closely-linked with the climate to which it is adapted. Tea growing regions of the above-mentioned countries have a climate which is similar to the cool, tropical conditions under which tea originated in the present-day India/Myanmar border region (Kingdon-Ward, 1950). However, at present tea is grown in a wide range of climates from Mediterranean to warm, humid tropics to include countries such as Russia and Georgia in the Northern latitudes and Argentina and Australia in the Southern latitudes. Tea is also grown across a range of altitudes from sea level up to about 2200 m a.s.l. (Carr, 1972).

Ecotypes: Commercially-grown tea are hybrids of two distinct 'ecotypes' (Wight, 1959), the Assam-type (known as 'Assam-jat') and China-type (China-jat). The China-type (var. sinensis) has small (3-6 cm long), relatively erect, dark-green leaves with a matt surface while the Assam-type (var. assamica) has larger $(15-20 \mathrm{~cm}$ long), more horizontally-held, light-green leaves with a glossy surface. While the Assam-type is believed to have originated under the shade of humid, tropical forests, the China-type is thought to have originated under open conditions in the cool, humid tropics (Carr and Stephens, 1992). Var. sinensis is known to be more resistant to drought than var. assamica. Because of intense interbreeding, commercial cultivars may have characters, which are intermediate between those of the two ecotypes, with Harler (1964) identifying nine different morphologically-different 'agrotypes'. Because of the distinct difference in the ecology of their origins, the two ecotypes and their hybrids exhibit considerable variation in their ecophysiology. For example, var. sinensis is known to be a hardier ecotype than var. assamica, being resistant to both cold (Fordham, 1977) and hot drought conditions (Harler, 1964). However, var. sinensis is considered to be inferior in both quantity and quality of yield (Harler, 1964). This variation in ecophysiology that exists in the tea germplasm can be used to develop cultivars specifically-suited to different climates.

Clonal and seedling tea: The tea plant has an economic life span of 50-60 years. However, some of the existing tea plantations are over 80-100 years old. Since the development of vegetative propagation (VP) for tea in the late $1950 \mathrm{~s}$, almost all new plantings of tea have been propagated vegetatively by stem cuttings. A major advantage of VP tea over 'seedling tea' (tea propagated by seed) is its greater uniformity in morphology and physiology. This uniformity coupled with the greater flexibility in selection and clonal development through vegetative propagation has also enabled the development of 'clones', which are substantially higher yielding than the seedling teas. However, the importance of seedling teas should not be ignored as they, present in various plantations and seed gardens, provide extremely valuable genetic diversity needed for crop improvement.

Selection of mother bushes of seedling for obtaining cuttings to develop high yielding clones has been a challenging task for breeders and plant physiologists. The early studies (Green, 1971) could not establish consistent correlations between the growth and yield parameters of the mother bushes and those of clones developed from them. However, subsequent work (Nyirenda, 1989, 1991; Smith et al., 1994) has shown adequately strong correlations between the bush area, shoot number and yield of mother bushes and those of their clones. Shanmugarajah et al. (1991) observed strong 
positive linear correlations between several growth attributes (i.e. plant height, number of side shoots, leaf area, girth of stem and stem dry weight) of 8- and 12month old nursery plants of a range of Sri Lankan tea clones and their respective yields in field-grown mature tea. Because of the importance of rooting ability for successful establishment of the clones, cuttings obtained from mother bushes are also tested for their rooting efficiency at the nursery stage. Because of the long time period involved in evaluation of a large number of clones before their release as 'cultivars', identification of physiological and morphological characters, which are responsible for high yield performance is extremely important. Yet, despite their common genetic origin, yield of clonal tea also shows significant variation in different environments (Wickramaratne, 1981).

Harvesting of tea: Tea plants can grow in to a $10-15 \mathrm{~m}$ tall tree (var. assamica) or a 5-8 m tall shrub (var. sinensis) if they are allowed to grow uninterrupted. However, in commercial plantations, tea is maintained as a bush of about $1 \mathrm{~m}$ tall, having a flat-topped foliage canopy with a depth of about $0.6 \mathrm{~m}$. Young shoots emerge from axillary buds near the top of the canopy (which is called the plucking table). These tender shoots are periodically (47 day intervals) plucked as yield when they have developed two or three leaves and a bud. Upon plucking of shoots, new shoots emerge from the axillary bud immediately below the plucking point.

Productivity and yield components of tea: The productivity of tea is quantified in terms of the weight of 'made tea' per unit land area per year. 'Made tea' refers to the form of tea obtained after the harvested (or 'plucked') shoot has gone through the manufacturing process (i.e. withering, fermenting and drying). Weight of made tea is directly related to the fresh weight of plucked shoot (2-3 leaves and a bud) by a factor of 0.2. Therefore, yield components of tea are the number of plucked shoots per unit land area $\left(\mathrm{N}_{\mathrm{sh}}\right)$ and the mean weight per shoot $\left(\mathrm{W}_{\mathrm{sh}}\right)$. Out of these two yield components, it is the variation of $\mathrm{N}_{\text {sh }}$ that has the stronger correlation with yield variation. The number of plucked shoots per unit land area is determined by the rate of shoot initiation whereas $\mathrm{W}_{\mathrm{sh}}$ is determined by the rate of shoot expansion. Although $\mathrm{N}_{\mathrm{sh}}$ has been identified as being the main factor responsible for the observed variation in tea yields between different genotypes, variation in the rate of shoot growth is the main parameter that causes season-to-season yield variation in a given genotype (Squire and Callander, 1981). In addition, both yield components are influenced by the duration between two successive harvests (known as the plucking round). Furthermore, $\mathrm{W}_{\mathrm{sh}}$ is also determined by the plucking standard adopted, i.e. whether two leaves and a bud or three leaves and a bud are plucked.

\section{Ecophysiological basis of growth and yield formation of} tea: Ecophysiology of tea can be discussed in terms of the primary physiological processes that are responsible for its growth (i.e. biomass production) and yield formation (i.e. shoot production). Rates of these primary physiological processes as determined by a range of genotypic and environmental factors determine the productivity (i.e. $\mathrm{kg}$ of made tea per hectare per year) of a given tea genotype (either seed- or vegetativelypropagated) growing in a given agro-ecological environment. Figure 1 illustrates a basic framework to describe the ecophysiological basis of yield determination of tea.

Ecophysiological research in tea has focused on three major sets of processes (Figure 1), which are intimatelylinked to tea yield: (a) Photosynthesis, biomass production and partitioning towards harvestable shoots; (b) Shoot initiation and extension; (c) Plant water relations and responses to drought and irrigation. The present review has attempted to synthesize the progress made in understanding the external (i.e. environmental) and internal (i.e. plant) control of the key processes mentioned above. A brief description of the possible impacts of long-term climate change is given at the end.

\section{PHOTOSYNTHESIS}

Basic features: Tea exhibits the $\mathrm{C}_{3}$ mechanism of photosynthesis (Roberts and Keys, 1978). Under normal ambient atmospheric conditions, rate of photorespiration in tea was around $19 \%$ of net photosynthesis. Tea leaves are the major plant organs where photosynthesis occurs, although the stems also contribute to $\mathrm{CO}_{2}$ assimilation (Sivapalan, 1975). However, the efficiency of $\mathrm{CO}_{2}$ fixation 


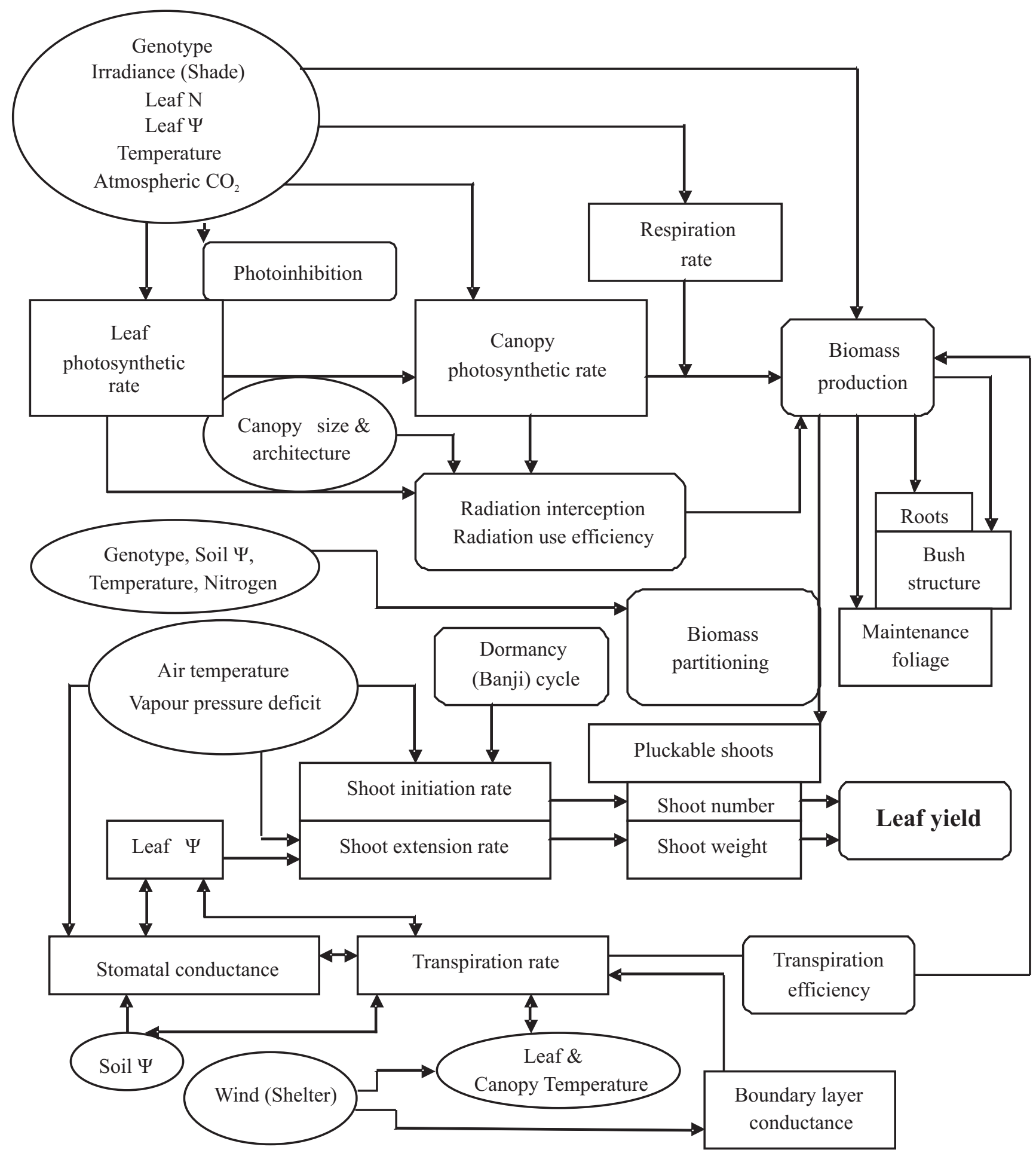

Figure 1. A framework showing the ecophysiological basis of yield determination of tea. Plant physiological characters and rates of physiological processes responsible for tea yield determination are shown within squares. External environmental factors and internal plant factors which influence the physiological processes are shown within ellipses. Physiological efficiencies and crop processes that are determined by several physiological processes at the cellular level are shown within rounded squares. Arrows indicate the directions of influence of external and internal factors on different physiological variables and processes. ( $\Psi-$ water potential) 
by mature brown stems is very low compared to that of leaves, and on a pruned stem, the newly emerging shoots draw this assimilated starch.

Light response of photosynthesis: Net photosynthetic rate $\left(\mathrm{P}_{\mathrm{n}}\right)$ of fully-expanded mature leaves of tea shows the typical asymptotic response to increasing light intensity. There is considerable variation in the reported saturating light intensities, ranging from 600-800 $\mu \mathrm{mol}$ (PAR) $\mathrm{m}^{-2} \mathrm{~s}^{-1}$ (Sakai, 1975; Squire, 1977; Gee et al., 1982; Mohotti, 2004) through $1000 \mu \mathrm{mol} \mathrm{m} \mathrm{m}^{-2} \mathrm{~s}^{-1}$ of PAR (Sakai, 1987; Smith et al., 1993a, 1994) up to $1200-1500 \mu \mathrm{mol} \mathrm{m}^{-2} \mathrm{~s}^{-1}$ ) (Okano et al., 1995). This indicates probable genotype $\mathrm{x}$ environment interaction effects.

Similarly, the light-saturated maximum rate of photosynthesis $\left(\mathrm{P}_{\max }\right)$ varies with genotype and environmental conditions under which tea is grown (Table 1). The reported values of $\mathrm{P}_{\text {max }}$ range from 2 to 11 $\mu \mathrm{mol} \mathrm{m} \mathrm{m}^{-2} \mathrm{~s}^{-1}$ (Squire, 1977; Roberts and Keys, 1978; Smith et al., 1993a, 1994; Jinke et al., 1999; Mohotti and Lawlor, 2002; Karunaratne et al., 2003). This is on par with the $\mathrm{P}_{\max }$ values obtained for some other perennial crops such as oil palm (Smith, 1989), cocoa (Balasimha et al., 1991), rubber (Gunasekara et al., 2007) and coconut (Nainanayke, 2004; Lakmini et al., 2006). However, there is no clear correlation between $\mathrm{P}_{\text {max }}$ and yield potential across the whole range of tea genotypes. Moreover, all parameters of the light response curve of a given cultivar show systematic variation with $\mathrm{N}$ supply and growth irradiance (Table 2) and at different stages of the pruning cycle (Table 3). Usually, $\mathrm{P}_{\max }$ declines during the latter part of the pruning cycle in parallel with an increased dark respiration rate. A description of the influence of environmental factors on photosynthesis of tea is given elsewhere.

Photoinhibition and shade adaptation of tea: As tea is thought to have originated as an understorey plant in the

Table 1. Response of light-saturated net photosynthetic rate (Pmax, $\mu$ mol $\left.\mathrm{CO}_{2} \mathrm{~m}^{2} \mathrm{~s}^{-1}\right)$, initial quantum efficiency (QE, $\left.\mu \mathrm{mol}^{-1} \mathrm{CO}_{2} \mu \mathrm{mol}^{-1} \mathrm{PAR}\right)$ and dark respiration rate $\left(\mathrm{R}_{\mathrm{d}}, \mu \mathrm{mol} \mathrm{CO} \mathrm{m}^{2} \mathrm{~s}^{-1}\right)$ to fertigation of different genotypes of tea. Fertigation $=$ drip irrigation with water and dissolved fertilizer; Control $=$ rainfed with fertilizer broadcasted. Within each genotype and variable, means with different letters indicate significant $(P<0.05)$ response to fertigation.

\begin{tabular}{lccccrr}
\hline & \multicolumn{2}{c}{$\mathrm{P}_{\text {max }}$} & \multicolumn{2}{c}{$\mathrm{QE}$} & $\mathrm{R}_{\mathrm{d}}$ \\
Genotype & Fertigation & Control & Fertigation & Control & Fertigation & Control \\
\hline TRI3072 & $10.8 \mathrm{a}$ & $9.5 \mathrm{~b}$ & $0.046 \mathrm{a}$ & $0.049 \mathrm{a}$ & $1.51 \mathrm{a}$ & $1.14 \mathrm{~b}$ \\
DN & $7.6 \mathrm{a}$ & $7.5 \mathrm{a}$ & $0.036 \mathrm{a}$ & $0.064 \mathrm{~b}$ & $0.21 \mathrm{a}$ & $1.34 \mathrm{~b}$ \\
DT1 & $4.7 \mathrm{a}$ & $3.3 \mathrm{~b}$ & $0.031 \mathrm{a}$ & $0.029 \mathrm{a}$ & $0.33 \mathrm{a}$ & $0.52 \mathrm{~b}$ \\
\hline
\end{tabular}

Table 2. Mean photosynthetic parameters (QE, quantum efficiency, $\mu \mathrm{mol}^{-1} \mathrm{CO}_{2} \mu \mathrm{mol}^{-1} \mathrm{PAR} ; \mathrm{P}_{\max }$, maximum light-saturated photosynthetic rate, $\mu$ mol $\mathrm{CO}_{2} \mathrm{~m}^{-2} \mathrm{~s}^{-1} ; \mathrm{R}_{\mathrm{d}}$, dark respiration rate, $\mu \mathrm{mol} \mathrm{CO} \mathrm{C}^{-2} \mathrm{~s}^{-1} ; d \mathrm{~A} / d C_{\mathrm{i}}$; , initial slope of the $\mathrm{P}_{\mathrm{n}}-C_{\mathrm{i}}$ curve; $\mathrm{V}_{\text {cmax, }}$ maximum rate of carboxylation of Rubisco, $\mu \mathrm{mol} \mathrm{CO} \mathrm{m}^{-2} \mathrm{~s}^{-1}$; and $\mathrm{RSL}$, relative stomatal limitation to photosynthesis, \%) of light and $\mathrm{CO}_{2}$ response curves of field-grown mature tea in Sri Lanka. HN = high-N application $\left(720 \mathrm{~kg} \mathrm{ha}^{-1} \mathrm{yr}^{-1}\right)$; $\mathrm{MN}=$ medium-N application $\left(360 \mathrm{~kg} \mathrm{ha}^{-1} \mathrm{yr}^{-1}\right) ; \mathrm{NN}=$ no-N application. Source: (Mohotti, 1998).

\begin{tabular}{|c|c|c|c|c|c|c|}
\hline Treatment & $\mathrm{QE}$ & $\mathrm{P}_{\max }$ & $\mathrm{R}_{\mathrm{d}}$ & $d \mathrm{~A} / d \mathrm{Ci}$ & $\mathrm{V}_{\mathrm{cmax}}$ & RSL \\
\hline no-shade, HN & 0.0256 & 9.70 & -1.555 & 0.0615 & 47.3 & 26.7 \\
\hline no-shade, MN & 0.0284 & 11.19 & -1.429 & 0.0662 & 47.3 & 26.5 \\
\hline no-shade, NN & 0.0248 & 7.09 & -1.376 & 0.0331 & 38.0 & 18.0 \\
\hline $35 \%$ shaded, HN & 0.0434 & 6.73 & -1.420 & 0.0916 & 45.4 & 38.2 \\
\hline $35 \%$ shaded, MN & 0.0300 & 10.26 & -1.184 & 0.0535 & 38.6 & 35.5 \\
\hline $35 \%$ shaded, NN & 0.0423 & 7.40 & -1.183 & 0.0664 & 66.9 & 40.8 \\
\hline $70 \%$ shaded, HN & 0.0282 & 10.19 & -1.165 & 0.0514 & 13.7 & 34.3 \\
\hline $70 \%$ shaded, MN & 0.0303 & 10.96 & -1.040 & 0.0605 & 46.9 & 29.8 \\
\hline $70 \%$ shaded, NN & 0.0293 & 9.88 & -1.153 & 0.0605 & 48.0 & 23.5 \\
\hline
\end{tabular}


Table 3. Variation of parameters of the photosynthetic light response curve $\left(\mathrm{P}_{\max }\right.$, maximum light-saturated photosynthetic rate, $\mu \mathrm{mol} \mathrm{CO} \mathrm{Cm}^{-2} \mathrm{~s}^{-1} ; \mathrm{R}_{\mathrm{d}}$, dark respiration rate, $\mu \mathrm{mol} \mathrm{CO} \mathrm{m}^{-2} \mathrm{~s}^{-1} ; \mathrm{QE}$, quantum efficiency, $\mu \mathrm{mol}^{-1} \mathrm{CO}_{2} \mu \mathrm{mol}^{-1} \mathrm{PAR}$; LCP, light

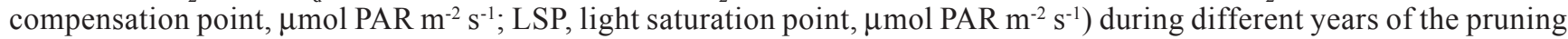
cycle of two genotypes of tea growing at high altitude (1380 m a.s.1.) in Sri Lanka. Parameters were estimated by fitting the asymptotic ( $\mathrm{R}^{2}$ is shown) exponential function (Boote and Loomis, 1991) to the light response curve.

\begin{tabular}{|c|c|c|c|c|c|c|}
\hline \multicolumn{7}{|c|}{ TRI 2025} \\
\hline Year & $\mathrm{P}_{\max }$ & $\mathrm{R}_{\mathrm{d}}$ & $\mathrm{QE}$ & LCP & LSP & $\overline{\mathrm{R}^{2}}$ \\
\hline 1 & 11.04 & -0.672 & 0.016 & 43.00 & 2229 & 0.94 \\
\hline 2 & 10.20 & -0.585 & 0.022 & 27.00 & 1496 & 0.96 \\
\hline 3 & 8.71 & -0.598 & 0.027 & 22.90 & 1055 & 0.93 \\
\hline 4 & 6.88 & -0.763 & 0.031 & 25.93 & 766 & 0.93 \\
\hline \multicolumn{7}{|c|}{ DT1 2005} \\
\hline & $\mathrm{P}_{\max }$ & $\mathrm{R}_{\mathrm{d}}$ & $\mathrm{QE}$ & LCP & LSP & $\mathrm{R}^{2}$ \\
\hline 1 & 10.95 & -1.048 & 0.030 & 36.54 & 1240 & 0.95 \\
\hline 2 & 10.12 & -0.456 & 0.031 & 15.04 & 1035 & 0.96 \\
\hline 3 & 9.28 & -0.671 & 0.032 & 21.71 & 955 & 0.94 \\
\hline 4 & 6.35 & -0.443 & 0.026 & 17.62 & 806 & 0.84 \\
\hline
\end{tabular}

tropical rainforests, it is likely that its photosynthetic apparatus is adapted to function with maximum capacity under shade. Investigations of photosynthetic partial processes (i.e. light capture, electron transport, photochemical- and non-photochemical energy quenching and carboxylation) by Mohotti et al. (2000) and Mohotti and Lawlor (2002) have shown that the entire photosynthetic apparatus of tea is shade-adapted. The rate of $\mathrm{P}_{\mathrm{n}}$, stomatal conductance $\left(g_{\mathrm{s}}\right)$ and apparent quantum yield (i.e. $P_{n}$ per unit of PAR absorbed) of 5month-old seedlings of tea grown in cabinets were consistently higher under shade (i.e. $150 \mu \mathrm{mol} \mathrm{PAR} \mathrm{m}^{-2} \mathrm{~s}^{-1}$ ) as compared to unshaded (i.e. $650 \mu \mathrm{mol}$ PAR $\mathrm{m}^{-2} \mathrm{~s}^{-1}$ ) conditions (Mohotti et al., 2000). Accordingly, several studies have shown that $\mathrm{P}_{\mathrm{n}}$ of tea decreases due to photoinhibition when the light intensity increases beyond 1400-1500 $\mu \mathrm{mol} \mathrm{m} \mathrm{m}^{-2} \mathrm{~s}^{-1}$ (Smith et al., 1993a; Mohotti and Lawlor, 2002). Furthermore, Smith et al. (1993a) observed an interaction between photoinhibition and $\mathrm{N}$ nutrition as only treatments that were receiving $\mathrm{N}$ fertilizer rates of $225 \mathrm{~kg} \mathrm{~N} \mathrm{ha}^{-1} \mathrm{yr}^{-1}$ or less showed photoinhibition at higher light intensities. Although treatments receiving higher $\mathrm{N}$ rates (e.g. $375 \mathrm{~kg} \mathrm{~N} \mathrm{ha}^{-1} \mathrm{yr}^{-1}$ ) showed light saturation around $1400 \mu \mathrm{mol} \mathrm{m}^{-2} \mathrm{~s}^{-1}$ of PAR, photoinhibition was not observed in the normal range of light intensities (i.e. up to $2000 \mu \mathrm{mol} \mathrm{m} \mathrm{m}^{-2} \mathrm{~s}^{-1}$ ). This is in agreement with the results of Mohotti and Lawlor (2002) who showed that photoinhibition of tea is minimized, but not completely eliminated, by abundant nitrogen supply.

Decreased $g_{\mathrm{s}}$ in response to increasing irradiance, leaf temperature $\left(\mathrm{T}_{\mathrm{L}}\right)$ and air vapour pressure deficit (VPD) played a key role in inducing photoinhibition of tea. In a field study on mature tea, Mohotti and Lawlor (2002) observed that increasing irradiance, $\mathrm{T}_{\mathrm{L}}$ and VPD with the progress of the day towards midday do decrease $\mathrm{g}_{\mathrm{s}}$ and sub-stomatal $\mathrm{CO}_{2}$ concentration $\left(C_{\mathrm{i}}\right)$, thus leading to reduced RuBP carboxylation and $P_{n}$. Reduced carboxylation channeled a greater percentage of excitation energy towards non-photochemical quenching and thereby increased photoinhibition. The lower rate of carboxylation owing to a smaller proportion of electrons allocated for carboxylation also contributes to the greater tendency for photoinhibition in tea (Mohotti et al., 2000). By following the diurnal variation patterns of the relevant variables, Mohotti and Lawlor (2002) showed that $\mathrm{P}_{n}$ did not recover from photoinhibition during late afternoon, despite $\mathrm{g}_{\mathrm{s}}$ and $C_{\mathrm{i}}$ increasing substantially due to lower irradiance, $T_{L}$ and VPD. However, overnight recovery of $P_{n}$ was observed.

The low $\mathrm{P}_{\max }$ of tea $\left(2-14 \mu \mathrm{mol} \mathrm{m} \mathrm{m}^{-2} \mathrm{~s}^{-1}\right)$ in comparison to most tropical plants $\left(20-40 \mu \mathrm{mol} \mathrm{m}^{-2} \mathrm{~s}^{-1}\right)$ has been related to a lower efficiency of photosystem II in capture of excitation energy and transport of electrons, as well as lower rates of linear electron transport (Mohotti et al., 
2000). Furthermore, it was found that a smaller proportion of the energy from electron transport supported carboxylation of ribulose bis-phosphate (RuBP) in tea. Tea also has low rates of RuBP carboxylation, and low amounts and activity of the key photosynthetic enzyme, ribulose bis-phosphate carboxylase-oxygenase (Rubisco). Further, the resistance imposed by stomata and mesophyll to diffusion of $\mathrm{CO}_{2}$ towards carboxylation sites is high, making less $\mathrm{CO}_{2}$ available for carboxylation. All these impose a source-limitation on tea yield.

Studies with young tea plants under controlled environmental conditions showed that shade increased $\mathrm{P}_{\mathrm{n}}$ by increasing the efficiency of PSII and the rate of linear electron transport (Mohotti et al., 2000). Furthermore, shade reduced photoinhibition by increasing $g_{s}$ (thus allowing greater $\mathrm{CO}_{2}$ influx) and thereby channeling a greater proportion of excitation energy towards carboxylation (i.e. increased photochemical quenching). Similar results have been also obtained in field studies on mature tea (Mohotti and Lawlor, 2000; Karunaratne et al., 2003).

Tea apparently possesses a large xanthophyll cycle pool, which may have a pivotal role in photoprotection. Violaxanthin, antheraxanthin and zeaxanthin were detected in fresh tea leaves at $15^{\circ} \mathrm{C}, 22^{\circ} \mathrm{C}$ and $30^{\circ} \mathrm{C}$; a large amount of xanthophyll pigments in de-epoxidation state were present in high sunlight (Wei et al., 2004). However, there is very little information on how these pigments could protect tea plants from photoinhibition under bright-light conditions, as occurs in full sun-grown teas in the field.

Implications for shade management in commercial tea plantations: In commercial plantations, partial shading is provided by growing tea plants under taller trees, i.e. shade trees, among the tea bushes at densities which are not too competitive with tea. Canopies of tall (10-15 m) trees such as Grevillea robusta and Albizzia moluccana and shrubs (about 3-5 m tall) such as Gliricidia sepium, Erythrina lithosperma and Acacia spp. provide partial shade at different times of the day depending on the direction of incident radiation. Interestingly, Karunaratne et al. (2003) observed significant photoinhibition on clear, sunny days, but not on cloudy days. Therefore, the extent of photoinhibition in a given agroecological region is determined by its proportion of clear, sunny days per year. In environments which have only a small proportion of clear, sunny days per year, giving too much shade could cause yield reductions due to a reduced radiation budget by the tea canopy. In a field study across a range of locations with different levels of natural shading, Gamage et al. (2007) have shown that the optimum shading level for tea growing at lower altitudes up to 600 $\mathrm{m}$ a.s.l. in the humid zone of Sri Lanka is between 30\% and $40 \%$.

\section{Internal factors influencing photosynthesis of tea}

In addition to the above-described internal factors related to photoinhibition of tea, several other internal factors influence $\mathrm{P}_{\mathrm{n}}$ of individual tea leaves. These are briefly described below.

Stomatal conductance: Stomatal conductance is a key internal factor affecting $\mathrm{P}_{\mathrm{n}}$ of tea. Because of the sensitivity of stomatal opening to several stimuli from the external environment (i.e. light intensity, water availability, $T_{L}$, VPD etc.), very often, $g_{s}$ mediates the response of $\mathrm{P}_{\mathrm{n}}$ to external factors as well. Generally, there is a positive relationship between $\mathrm{P}_{n}$ and $g_{\mathrm{s}}$ because increased stomatal opening (i.e. higher $\mathrm{g}_{\mathrm{s}}$ ) allows a greater flux of $\mathrm{CO}_{2}$ for photosynthesis and vice versa. However, when the internal photosynthetic capacity is reduced due to environmental stresses such as drought or internal factors such as shade adaptation or leaf ageing, $g_{s}$ may be lower because of the lower photosynthetic capacity. Smith et al. (1993a) observed a highly significant positive correlation between $\mathrm{g}_{\mathrm{s}}$ and $\mathrm{P}_{\mathrm{n}}$ [measured at air temperature $\left(\mathrm{T}_{\mathrm{a}}\right)>15^{\circ} \mathrm{C}$ and PAR $>1000$ $\mu \mathrm{mol} \mathrm{m} \mathrm{m}^{-2} \mathrm{~s}^{-1}$, for the range of $\mathrm{g}_{\mathrm{s}}$ between 8 and $100 \mathrm{mmol}$ $\mathrm{H}_{2} \mathrm{O} \mathrm{m}^{-2} \mathrm{~s}^{-1}$. Within this range, $\mathrm{P}_{\mathrm{n}}$ increased by $42.6 \times 10^{-3}$ $\mu \mathrm{mol} \mathrm{CO}{ }_{2}$ per mmol ${ }^{-1} \mathrm{H}_{2} \mathrm{O}$. Smith et al. (1994) also observed a similar positive correlation between $\mathrm{P}_{\mathrm{n}}$ and $\mathrm{g}_{\mathrm{s}}$ inasmuch as $g_{\mathrm{s}}$ was below $30 \mathrm{mmol} \mathrm{H}_{2} \mathrm{O} \mathrm{m}^{-2} \mathrm{~s}^{-1}$. In addition to affecting $\mathrm{P}_{\mathrm{n}}, g_{\mathrm{s}}$ also influences transpiration and plays a pivotal role in determining the water status tea leaves. Stomatal conductance is, in turn, influenced by the leaf water status and soil water status. The interplay between $\mathrm{P}_{\mathrm{n}}, g_{\mathrm{s}}$ and external environmental factors such as $\mathrm{T}_{\mathrm{L}}$ and water availability are discussed elsewhere in this paper.

Leaf age: In a commercially-managed tea bush, the vegetative shoots are removed at short intervals by 
plucking. In young expanding leaves, photosynthetic capacity (as quantified by $\mathrm{P}_{\max }$ ) and efficiency (quantified as photosynthetic activity per unit leaf weight) develops gradually. Therefore, the young buds and shoots are dependent on the mature leaves for their supply of assimilates. Hence, a layer of mature leaves, called 'maintenance foliage' is left on the tea bush.

Variation of $\mathrm{P}_{\mathrm{n}}$ with leaf age has been studied by many workers (Barua, 1960; Sanderson and Sivapalan, 1966a, b; Manivel and Hussain, 1982; Okano et al., 1996; Raj Kumar et al., 1998). As leaf matures $P_{n}$ gradually increases, reaching a maximum when shoots are ready for harvesting. In a study conducted in Sri Lanka, using ${ }^{14} \mathrm{C}$ on detached tea leaves, photosynthetic efficiency was shown to increase until the leaves reached about half their mature size, i.e. $c a$. 36-d-old (Sanderson and Sivapalan, 1966a). Leaf age was also found to have a marked effect on the type of compounds synthesized from photosynthetically-assimilated carbon. In immature leaves, a relatively large proportion of the assimilated carbon was incorporated into flavanols (catechins) and compounds which would be utilized in situ (amino acids, organic acids, etc.). In mature leaves, most of the assimilated carbon was incorporated into easily translocatable substances, such as sugars. Hence, the mature foliage of tea bushes was shown to nurture the immature parts of the plant by supplying them with carbon compounds. In intact bushes, carbon assimilated by mature leaves was shown to support the flush (i.e. the harvested immature shoots) and roots. It readily moves into the developing shoot tips, and become generally distributed in about $24 \mathrm{~h}$ (Sanderson and Sivapalan, 1966b). Photosynthates produced in immature leaves do not move out of them. However, older leaves do not become parasitic on other leaves when they become unproductive.

\section{External factors influencing photosynthesis of tea}

Leaves of different plant species have evolved to exploit and cope with a remarkably wide range of environments. They are able to do this by adaptation of their anatomy, biochemistry and physiology. Light, water and nutrition are the major environmental factors affecting photosynthesis of tea.

Light intensity and shade: The influence of light intensity on $\mathrm{P}_{\mathrm{n}}$ of tea has been discussed elsewhere.
Shade can influence $\mathrm{P}_{\mathrm{n}}$ indirectly by regulating leaf and canopy temperatures (Hadfield, 1975; Gee et al., 1982; Sivapalan, 1993; Mohotti and Lawlor, 2002). For example, shade reduced $\mathrm{T}_{\mathrm{L}}$ by $10-12^{\circ} \mathrm{C}$ at midday, in a drought susceptible clone (Gee et al., 1982). Under the warm, tropical conditions found in Sri Lanka and India, shading reduces $T_{L}$, which is likely to exceed the optimum for $P_{n}$ on sunny days. However, in certain other parts of the world, for example in the cool highlands of Kenya, where sub-optimal temperatures prevail, shade is not considered necessary (Sivapalan, 1993; Smith et al., 1993a).

Air and leaf temperatures: Maximum $\mathrm{P}_{\mathrm{n}}$ of tea leaves occurs at $30-35^{\circ} \mathrm{C}$ in North East India (Hadfield, 1975). Photosynthesis rapidly fell beyond $37^{\circ} \mathrm{C}$ and there was no net photosynthesis at $42^{\circ} \mathrm{C}$. Under natural conditions, when fully exposed to sun, $T_{L}$ is $2-12^{\circ} \mathrm{C}$ higher than $T_{a}$. Leaf temperature in tea is influenced by size, structure and pose of the leaf, wind velocity, relative humidity and rate of transpiration (Rahman, 1988). Mohotti and Lawlor (2002) reported that the capacity for $\mathrm{CO}_{2}$ assimilation in tea was decreased by increased temperature brought about by high irradiance as the day progressed from morning to early afternoon. The high rates of $\mathrm{P}_{\mathrm{n}}$ were $37 \%$ higher in the morning with cooler temperatures around $20^{\circ} \mathrm{C}$, than at $30^{\circ} \mathrm{C}$ in the afternoon. In this experiment, $\mathrm{P}_{\mathrm{n}}$ decreased with increasing $\mathrm{T}_{\mathrm{a}}$ in the range between $20^{\circ} \mathrm{C}$ and $30^{\circ} \mathrm{C}$.

Responses of photosynthesis to $\mathrm{T}_{\mathrm{a}}$ are cultivardependent, as shown under South Indian conditions (Joshi and Palni, 1998). In four out of six cultivars tested, the optimum $\mathrm{T}_{\mathrm{a}}$ for maximum $\mathrm{P}_{\mathrm{n}}$ was shown to be $25^{\circ} \mathrm{C}$. Beyond this temperature, $\mathrm{P}_{\mathrm{n}}$ dropped drastically. For the other two cultivars, the optimum was $30^{\circ} \mathrm{C}$ and, interestingly, $\mathrm{P}_{\mathrm{n}}$ did not drop as drastically as in the other cultivars. Furthermore, the two cultivars having a higher temperature optimum had higher $\mathrm{g}_{\mathrm{s}}$ and water-use efficiency than the others at all $\mathrm{T}_{\mathrm{a}}$ tested, indicating heat tolerance.

Smith et al. (1993a, 1994) investigated the interplay between $\mathrm{P}_{\mathrm{n}}, g_{\mathrm{s}}$ and $\mathrm{T}_{\mathrm{L}}$ through a combination of irrigation and nitrogen fertilizer treatments. In well-irrigated tea, maximum $P_{n}$ was at an optimum range of $20-30^{\circ} \mathrm{C}$, beyond which $\mathrm{P}_{n}$ decreased at a rate of $0.053 \mu \mathrm{mol} \mathrm{m}^{-2} \mathrm{~s}^{-1}{ }^{\circ} \mathrm{C}^{-1}$. In poorly-irrigated tea, optimum $T_{L}$ was around $20-24^{\circ} \mathrm{C}$ and rate of reduction of $\mathrm{P}_{n}$ was greater (i.e. $0.093 \mu \mathrm{mol} \mathrm{m}^{-2} \mathrm{~s}^{-1}$ 
$\left.{ }^{\circ} \mathrm{C}^{-1}\right)$. However, in contrast, Smith et al. (1993a) observed that $\mathrm{P}_{\mathrm{n}}$, when averaged across all irrigation and nitrogen fertilizer treatments, remained approximately constant between $20^{\circ} \mathrm{C}$ and $36^{\circ} \mathrm{C}$. Sakai (1987) also reported stable $\mathrm{P}_{\mathrm{n}}$ for field-grown tea in the $\mathrm{T}_{\mathrm{a}}$ range of $10-35^{\circ} \mathrm{C}$. Measurements of changes in $g_{s}$ along with the abovementioned variation of $\mathrm{P}_{n}$ revealed some insights on stomatal control of photosynthesis. In the work of Smith et al. (1993a), $g_{\mathrm{s}}$ showed a gradual decline with increasing $\mathrm{T}_{\mathrm{L}}$ within the range between $15^{\circ}$ and $35^{\circ} \mathrm{C}$, at a rate of 0.2 mmol m${ }^{-2} \mathrm{~s}^{-1}{ }^{\circ} \mathrm{C}^{-1}$. The ratio of $\mathrm{P}_{\mathrm{n}}$ to $g_{\mathrm{s}}$ (which is related to instantaneous transpiration efficiency) increased with increasing $\mathrm{T}_{\mathrm{L}}$ up to $36^{\circ} \mathrm{C}$ (Smith et al., 1993a) and $27^{\circ} \mathrm{C}$ (Smith et al., 1994). Both Hadfield (1975) and Sakai (1987) found similar optimum-type relationships between $\mathrm{P}_{\mathrm{n}} / \mathrm{g}_{\mathrm{s}}$ and $\mathrm{T}_{\mathrm{L}}$ for field- and indoor-grown tea with optimum $\mathrm{T}_{\mathrm{L}}$ of $35^{\circ} \mathrm{C}$ and $25^{\circ} \mathrm{C}$, respectively.

Whereas the response of $\mathrm{P}_{n}$ to higher $\mathrm{T}_{\mathrm{a}}$ is important for tea growing at lower altitudes and under unshaded conditions, $\mathrm{P}_{\mathrm{n}}$ at lower $\mathrm{T}_{\mathrm{a}}$ become important for tea growing at cooler higher altitudes. Smith et al. (1993a) observed that $\mathrm{P}_{\mathrm{n}}$ of tea at $17^{\circ} \mathrm{C}$ was only $21 \%$ of that at $28^{\circ} \mathrm{C}$. The $\mathrm{T}_{\mathrm{a}}$ at which $\mathrm{P}_{\mathrm{n}}$ reaches zero has been shown to vary between $11^{\circ} \mathrm{C}$ and $16^{\circ} \mathrm{C}$ (Sakai, 1975; Manivel, 1980; Smith et al., 1993a, 1994).

$\mathrm{CO}_{2}$ concentration: Response of $\mathrm{P}_{\mathrm{n}}$ to variation of the atmospheric $\mathrm{CO}_{2}$ concentration $\left(C_{\mathrm{a}}\right)$ is important not only to determine spatial and temporal variations of leaf $\mathrm{P}_{n}$, but also to determine how the productivity of tea would respond to long-term climate change with increasing $C_{\mathrm{a}}$. Smith et al. (1993a) observed a positive, linear correlation between instantaneous $\mathrm{P}_{n}$ and $\mathrm{CO}_{2}$ concentration of their measurement chamber (which varied between 351 to 490

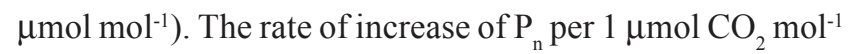
was $8.16 \times 10^{-3} \mu \mathrm{mol} \mathrm{m} \mathrm{m}^{-2} \mathrm{~s}^{-1}$. Anandacoomaraswamy et al. (1996) showed that $\mathrm{P}_{\max }$ of tea can be raised temporarily up to $40-60 \mu \mathrm{mol} \mathrm{m} \mathrm{m}^{-2} \mathrm{~s}^{-1}$ by artificial $\mathrm{CO}_{2}$ enrichment of the measurement chamber up to $1500 \mu \mathrm{mol} \mathrm{mol}^{-1}$. Maximum $\mathrm{P}_{\mathrm{n}}$ around $30 \mu \mathrm{mol} \mathrm{m} \mathrm{m}^{-2} \mathrm{~s}^{-1}$ was reached around 1000-1200 $\mu \mathrm{mol}$ $\mathrm{mol}^{-1} \mathrm{Ci}$ in mature, field-grown tea (Mohotti, 1998). The corresponding values for young, container-grown tea were $7-10 \mu \mathrm{mol} \mathrm{m}^{-2} \mathrm{~s}^{-1}$ and 500-600 $\mu \mathrm{mol} C_{\mathrm{i}} \mathrm{mol}^{-1}$. Parameters of the $\mathrm{CO}_{2}$ response curves of field-grown, mature tea varied with different shade and $\mathrm{N}$ levels (Table 2).
Mineral nutrition: Photosynthesis of tea is strongly related to leaf N (Aoki, 1987; Sakai, 1987; Anandacoomaraswamy et al., 2002). Photochemical efficiency at low irradiance (i.e. quantum efficiency, QE) and $\mathrm{P}_{\max }$ of tea seedlings grown in nutrient solutions increased with increasing N supply up to $105 \mathrm{ppm} \mathrm{N} \mathrm{(De}$ Costa et al., 2000). While the response of $\mathrm{P}_{\max }$ was observed immediately after applying the $\mathrm{N}$ treatments, the response of QE was observed after one month. A hyperbolic relationship of $\mathrm{P}_{\max }$ with leaf $\mathrm{N}$ content (LN) was observed: it was positive above a threshold $\mathrm{LN}$ of $2 \%$ (dry matter basis) and reached a plateau around 2.9\% LN. The QE was very low (i.e. around $0.01 \mu \mathrm{mol} \mathrm{CO} \mathrm{Cmol}^{-1}$ PAR) at LN below 2.8\%. As LN increased above $2.8 \%$, QE increased rapidly and reached a plateau around 3.2\% LN. Measurements carried out in a long-term experiment on differential N, P, K application to mature tea showed high $\mathrm{P}_{\text {max }}$ with 112 and $224 \mathrm{~kg} \mathrm{~N} \mathrm{ha}^{-1}$ year $^{-1}$ (10.7 and $9.9 \mu \mathrm{mol}$ $\mathrm{m}^{-2} \mathrm{~s}^{-1}$ respectively) compared to $336 \mathrm{~kg} \mathrm{~N} \mathrm{ha}^{-1}$ year $^{-1}(5.8$ $\mu \mathrm{mol} \mathrm{m} \mathrm{m}^{-2} \mathrm{~s}^{-1}$ (Mohotti, 1998). Information on the effects of other nutrient elements on $\mathrm{P}_{\mathrm{n}}$ of tea is scarce. Krishnapillai and Ediriweera (1986) observed that increased application of $\mathrm{N}$ and $\mathrm{K}$ increased the chlorophyll content in both flush (i.e. immature) and mature leaves. Chlorophyll is known to contribute to the blackness of made tea. In another study carried out with container-grown young tea, spraying of $2 \% \mathrm{~K}_{2} \mathrm{SO}_{4}$ improved drought tolerance of cultivars TRI 2026 and TRI 4049 presumably through an osmotic adjustment (Mohotti et al., 2003a).

Water deficits: Anandacoomaraswamy et al. (1996) observed that $\mathrm{P}_{\max }$ decreased as the soil water potential $\left(\psi_{\mathrm{w}}\right)$ decreased from -0.01 to $-2.0 \mathrm{MPa}$ in 9-month-old tea plants from two cultivars. Whereas $\mathrm{P}_{\max }$ of a droughtsusceptible cultivar decreased from 9.3 to $0.7 \mu \mathrm{mol} \mathrm{m}^{-2} \mathrm{~s}^{-1}$, the corresponding reduction in a relatively droughttolerant cultivar was from 6.5 to $2.3 \mu \mathrm{mol} \mathrm{m} \mathrm{m}^{-2} \mathrm{~s}^{-1}$. In both cultivars, the contribution of non-stomatal (i.e. biochemical) effects to the reduction of $\mathrm{P}_{n}$ with increasing water stress was remarkably greater than that of stomatal effects, respectively $70-98 \%$ and $2-30 \%$. Anandacoomaraswamy et al. (1996) further showed that $\mathrm{P}_{\max }$ of water-stressed tea leaves could be raised by artificial $\mathrm{CO}_{2}$ enrichment of the measurement chamber. 
In container-grown, young tea plants, $g_{\mathrm{s}}$ decreased with decreasing $\psi_{\text {leaf }}$, resulting in decreases in $C_{\mathrm{i}}, \mathrm{P}_{\mathrm{n}}$ and midday efficiency of PSII in capturing actinic light $\left(\Phi_{\text {EXC }}\right)$, and increases in proline content in four cultivars (Gunawardena et al., 2001). Osmotic adjustment with increased total soluble sugar contents could be observed only in two of the cultivars. Mohotti et al. (2000) showed that $\mathrm{P}_{\mathrm{n}}, g_{\mathrm{s}}, \mathrm{F}_{\mathrm{v}} / \mathrm{F}_{\mathrm{m}}$ and $\Phi_{\text {EXC }}$ decreased gradually with decreasing $\psi_{\text {leaf }}$.

Smith et al. (1993a) showed that when averaged across the different fertilizer treatments, abundant irrigation did increase $\mathrm{P}_{\mathrm{n}}$ of mature, field-grown tea by $19 \%$ when compared to the rainfed treatment. In contrast, Smith et al. (1994) observed a $258 \%$ increase in $\mathrm{P}_{\mathrm{n}}$ in fullyirrigated tea as compared to rainfed, drought-stressed tea. In both studies, irrigation caused a parallel increase of $g_{\mathrm{s}}$ as well. However, the increase of $\mathrm{P}_{\mathrm{n}}$ was proportionately greater than that of $g_{\mathrm{s}}$ (e.g. $81 \%$ in Smith et al., 1994), causing an increase of $\mathrm{P}_{\mathrm{n}} / \mathrm{g}_{\mathrm{s}}$ ratio with irrigation.

Canopy photosynthesis: Overall canopy photosynthesis $\left(\mathrm{P}_{\mathrm{c}}\right)$ is the sum of the product between $\mathrm{P}_{\mathrm{n}}$ and surface area of all individual leaves of the canopy. A strong relationship exists between $\mathrm{P}_{\mathrm{n}}$ and light intensity incident on a given leaf located at a given canopy depth. Therefore, distribution of incident radiation within the canopy through light penetration along with $\mathrm{P}_{n}$ as determined by the internal and external factors discussed above determine the magnitude of $\mathrm{P}_{\mathrm{c}}$. Using ${ }^{13} \mathrm{CO}_{2}$, Okano et al. (1995) showed that $85 \%$ of $\mathrm{P}_{\mathrm{c}}$ of tea growing in autumn in Japan was carried out by the top $5 \mathrm{~cm}$ leaf layer of the canopy and that the maximum canopy depth effective for photosynthesis was only $10 \mathrm{~cm}$. However, Okano et al. (1996) concluded that in spring, at the plucking stage, nearly $90 \%$ of $\mathrm{P}_{\mathrm{c}}$ was conducted by developing new leaves and the contribution by overwintering mature leaves was only $10 \%$.

Smith et al. (1993a) computed $\mathrm{P}_{\mathrm{c}}$ by dividing the canopy in to five types of leaves (depending on their maturity) and summing the product between $\mathrm{P}_{n}$ and fraction of radiation interception of each layer. The rate of $\mathrm{P}_{\mathrm{n}}$ was highest in the fully-expanded, dark-green, mature leaves on the plucking table, with both the younger leaves above them and the older leaves below them showing lower $\mathrm{P}_{\mathrm{n}}$. However, there was no significant variation in $g_{\mathrm{s}}$ between different types of maintenance foliage. The fully-expanded, dark-green, mature leaves also showed the highest fraction of radiation interception and therefore made the highest contribution towards $\mathrm{P}_{\mathrm{c}}$. These leaves also had the highest $\mathrm{P}_{\mathrm{n}} / \mathrm{g}_{\mathrm{s}}$ ratio indicating that their instantaneous transpiration efficiency was also highest. The combined effects of irrigation and $\mathrm{N}$ fertilizer increased $\mathrm{P}_{\mathrm{c}}$ by $26 \%$ over the unirrigated, non-fertilized tea.

W.A.J.M. De Costa et al. (unpublished results) computed daily canopy gross photosynthetic rates $\left(\mathrm{P}_{\mathrm{g}}\right)$ by a layered canopy model, where the photosynthetic light response curves and partial leaf area indices were measured separately. For two genotypes of tea growing at high altitude (1400 m a.s.1.) in Sri Lanka under 35\% shade [which has been found to be around the optimum by Gamage et al. (2007)], $\mathrm{P}_{\mathrm{g}}$ varied between 16.85 to 26.51 $\mathrm{g} \mathrm{CO}_{2} \mathrm{~m}^{-2}$ [land area] $\mathrm{d}^{-1}$ across different years of the pruning cycle. Corresponding variation of canopy leaf area index (LAI) was 3.11-6.69. The above range of $\mathrm{P}_{\mathrm{g}}$ is comparable to that of 13-26 $\mathrm{g} \mathrm{CO}_{2} \mathrm{~m}^{-2}$ [land area] $\mathrm{d}^{-1}$ found by Squire (1977) for tea growing in Malawi and having a LAI of 5-6. In agreement with the findings of Okano et al. (1995, 1996), De Costa et al. (unpublished results) also found that the top two layers (i.e. $0-10 \mathrm{~cm}$ and $10-20 \mathrm{~cm}$ canopy depths) contributed $80-90 \%$ of $\mathrm{P}_{\mathrm{g}}$ (Figures $2 \mathrm{~A}$ and $3 \mathrm{~A})$. However, there was an appreciable variation between the two cultivars in their distribution of $\mathrm{P}_{\mathrm{g}}$ among the different canopy layers despite there being no significant difference in the corresponding distribution of partial LAI (Figure 2B). In the cultivar TRI 2025, the middle- (10-30 cm canopy depths) and bottom canopy layers contributed a slightly greater proportion to overall canopy $\mathrm{P}_{\mathrm{g}}$ than the corresponding layers in the cultivar DT1. This could be related to the difference in canopy architecture with TRI 2025 having a lower canopy light extinction coefficient $(\mathrm{k}=0.646)$ than DT1 $(\mathrm{k}=0.815)$, thus indicating a greater light penetration into the canopy. This was confirmed by measurements of light interception, which showed that the top layer of DT1 intercepted a much greater proportion of light (i.e. $82 \%$ ) than the top layer of TRI 2025 (66\%) (Figure 3B). On the other hand, TRI 2025 had greater proportional light interception in all other canopy layers. It should be noted that in the top layer of both cultivars, the proportional contribution to $\mathrm{P}_{\mathrm{g}}$ was lower than their respective 
proportional light interception. This indicates that light saturation had occurred in leaves of the top canopy layer. Conversely, in both genotypes, in the second canopy layer (10-20 cm canopy depth), the proportional contribution to $\mathrm{P}_{\mathrm{g}}$ was greater than its share of intercepted light. This could probably be because of better adaptation of the photosynthetic apparatus to the lower light intensities penetrating in to the second canopy layer.

Importance of photosynthetic capacity in yield determination of tea: There have been some conflicting opinions on how important the photosynthetic rate is in determining the productivity of tea. Based on evidence compiled from several studies, Squire and Callander
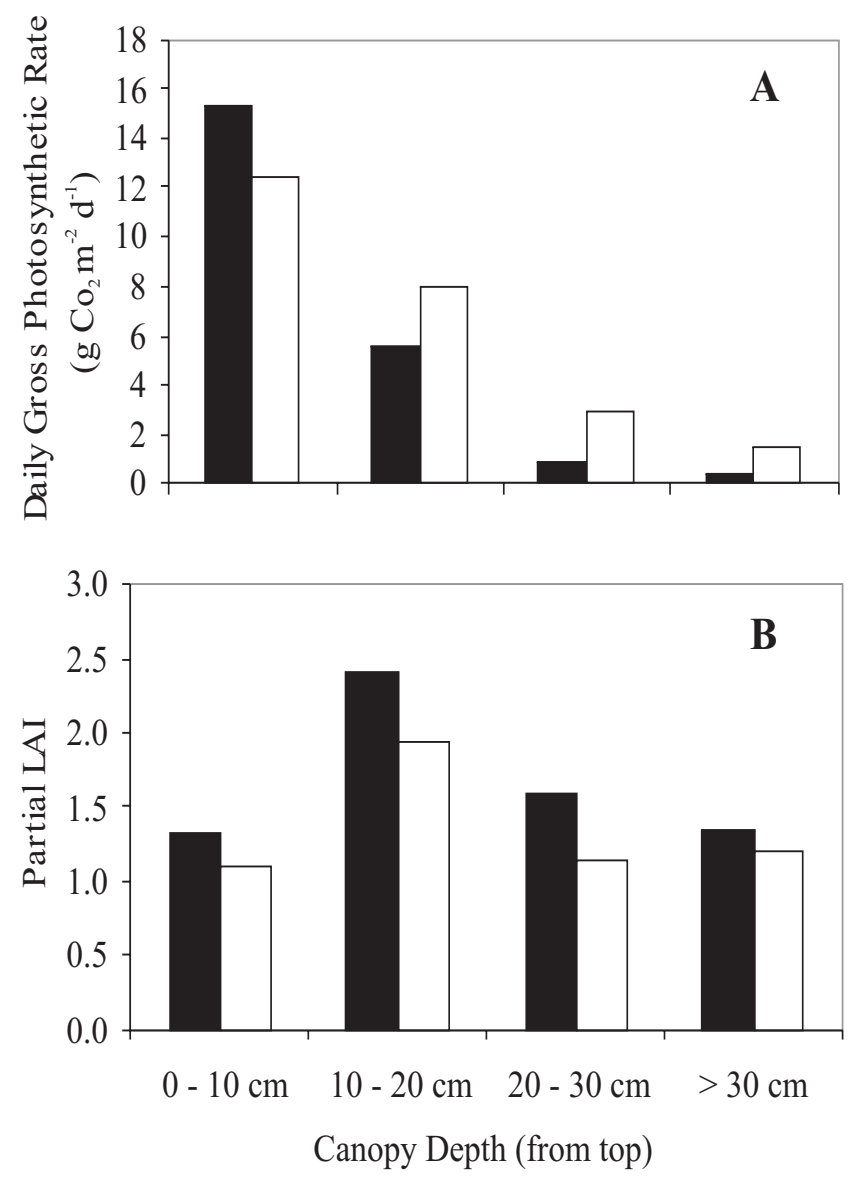

Figure 2. Distribution of daily gross photosynthesis (A) and partial leaf area index (B) in different layers of the canopy during the second year of the pruning cycle in cultivars DT1 (filled bars) and TRI2025 (open bars). (Source: W.A.J.M. De Costa, D.M.S. Navaratne and A. Anandacoomaraswamy, unpublished results).
(1981) concluded that the current rate of $\mathrm{P}_{n}$ is not directly linked to leaf yield of tea. The basis of their argument was that leaf yield of tea is controlled more by the rates of shoot initiation and extension rather than by the supply of assimilates from current $\mathrm{P}_{\mathrm{n}}$. Rates of shoot initiation and extension are primarily controlled by $\mathrm{T}_{\mathrm{a}}$ and VPD and shoot turgor (Squire, 1979) whereas $P_{n}$ is primarily controlled by light intensity. Moreover, the weight of harvested shoots of tea (i.e. 2-3 leaves and a bud) is only a small fraction (0.05-0.15) of its total biomass production (Callander, 1978; Tanton, 1979). Therefore, both Tanton (1979) and Squire and Callander (1981) argued that assimilate supply cannot be a limiting factor in yield determination, when harvested yield is such a small fraction of total biomass production. Instead, tea leaf yield per unit land area is strongly correlated with $\mathrm{N}_{\text {sh }}$. Hence, Tanton (1979) concluded that tea yield is sinklimited rather than source-limited. Based on the results of a simulation model, Matthews and Stephens (1998a) also suggest that assimilate supply is unlikely to limit shoot growth under most conditions. However, it should be borne in mind that photoinhibition could reduce sourcecapacity and thereby could impose a source-limitation as well on tea yield (Mohotti et al., 2000; Mohotti and Lawlor, 2002).

Squire and Callander (1981) also cite the frequent observation of higher $\mathrm{P}_{\mathrm{n}}$ even during periods of low shoot growth rates due to higher VPD or cooler $\mathrm{T}_{\mathrm{a}}$ (Squire, 1979) or higher soil water deficits (Stephens and Carr, 1991a) as evidence for the independence of tea yield from $P_{n}$. However, Smith et al. (1993a) argue that assimilates produced during periods of slow shoot growth are subsequently used during periods of higher shoot growth. Hence, although tea yield may not be correlated with current $P_{n}$, over a longer-time period, time-integrated tea yield and $\mathrm{P}_{\mathrm{n}}$ should be positively correlated.

Respiratory losses of photoassimilates: Respiration is the process of generating metabolic energy for synthesis of new biomass ('growth respiration') and maintenance of existing biomass ('maintenance respiration'). Respiration rate also influences growth rates of a crop as respiration uses part of the photoassimilates as the substrate. Tanton (1979) estimated that mature tea which accumulates biomass at a rate of $17.5 \mathrm{t} \mathrm{ha}^{-1} \mathrm{yr}^{-1}$ uses $67 \%$ of its photoassimilates for respiration. Hadfield (1974) 

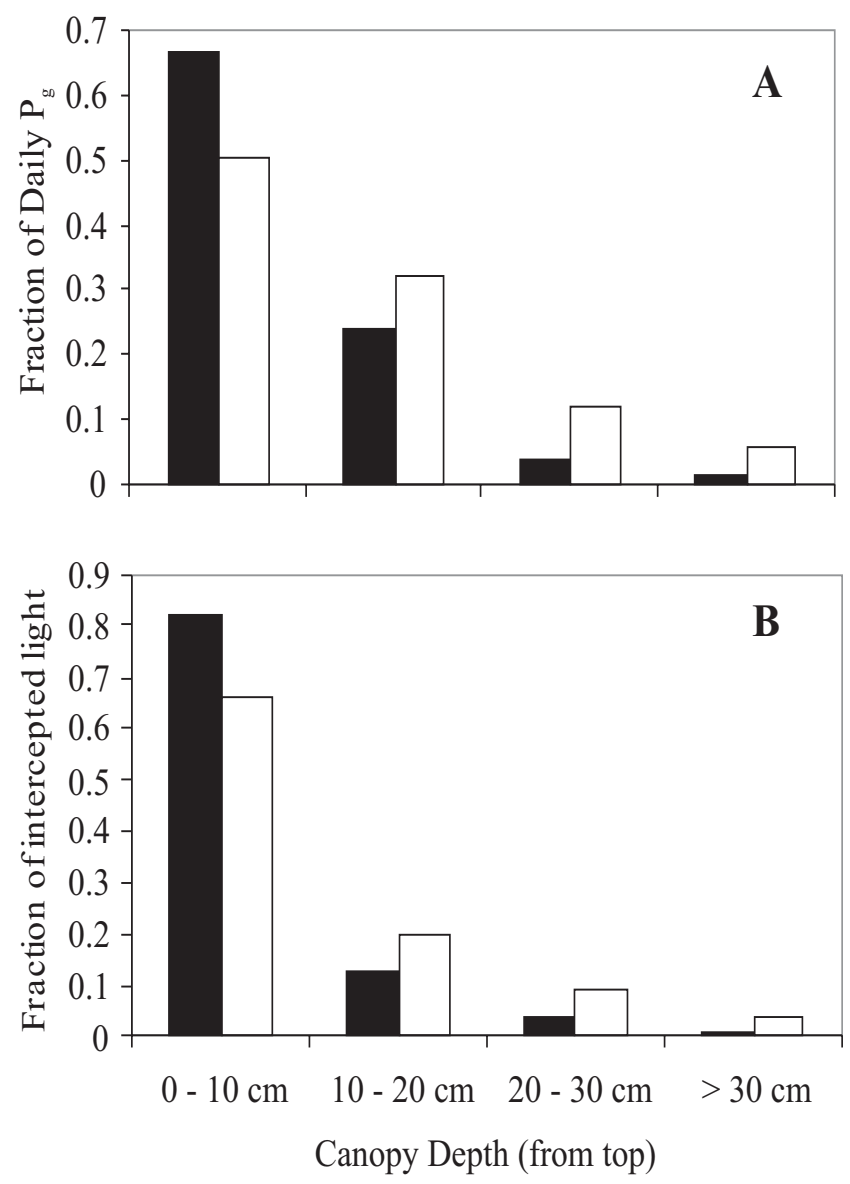

Figure 3. Distribution of fraction of daily total gross photosynthesis $\left(\mathrm{P}_{\mathrm{g}}\right)(\mathbf{A})$ and fraction of total intercepted radiation (B) in different layers of the canopy during the second year of the pruning cycle in cultivars DT1 (filled bars) and TRI2025 (open bars). (Source: W.A.J.M. De Costa, D.M.S. Navaratne and A. Anandacoomaraswamy, unpublished results).

estimated the respiratory losses to be $85 \%$. The estimate of Tanton (1979) agrees with the measurements of Barbora and Barua (1988) on six cultivars of mature tea under plucking in North East India, where only $36 \%$ of photoassimilates remained in the plant, and the balance $64 \%$ were lost in metabolic respiration. These respiratory losses are much greater than those of annual crops (i.e. 30-50\%, Charles-Edwards, 1982). It was further observed that respiration in all plant organs increased linearly as the temperature increased from $20^{\circ} \mathrm{C}$ to $40^{\circ} \mathrm{C}$. Respiratory losses of higher yielding cultivars were higher than those of the lower yielding cultivars. Because of the increase in total biomass with time during the period between two successive prunings, maintenance respiration increases as the crop progresses through a pruning cycle (Navaratne et al., unpublished results). Using young tea (9-month-old) seedlings growing in sand culture, Anandacoomaraswamy et al. (2002) estimated the respiratory cost of tea roots for maintenance and nitrate uptake as $0.324 \mu \mathrm{mol} \mathrm{CO}_{2} \mathrm{~kg}^{-1}$ (root dry matter) $\mathrm{s}^{-1}$ and 0.64 mol $\mathrm{CO}_{2}(\mathrm{~mol} \mathrm{~N})^{-1}$, respectively. Root respiration rates increased with increasing $\mathrm{N}$ supply, primarily because of the increased respiratory cost for nitrate uptake. De Costa et al. (unpublished results) estimated daily growth respiration to vary from 4.42 to $6.96 \mathrm{~g} \mathrm{CO}_{2} \mathrm{~m}^{-2}$ (land area) $\mathrm{d}^{-1}$ in two cultivars of mature, field-grown tea at high altitude in Sri Lanka. These rates varied for different years of the pruning cycle. This variation was positively correlated with the variation of the rates of biomass production in different years.

\section{BIOMASS PRODUCTION OF TEA}

Direct measurement of total biomass of mature tea growing in the field is difficult, mainly because of the difficulty of recovering all roots. Measured or estimated rates of total biomass production of tea range from 9.43$11.40 \mathrm{t} \mathrm{ha}^{-1} \mathrm{yr}^{-1}$ (Burgess and Carr, 1993) through 15-18 t ha $^{-1} \mathrm{yr}^{-1}$ (Tanton, 1979; Magambo and Cannell, 1981; Navaratne et al., unpublished results) up to $21.5 \mathrm{t} \mathrm{ha}^{-1} \mathrm{yr}^{-1}$ (Burgess and Sanga, 1994; Matthews and Stephens, 1998a). However, these rates are lower than those of other $\mathrm{C}_{3}$ crops (25-40 $\left.\mathrm{t} \mathrm{ha}^{-1} \mathrm{yr}^{-1}\right)$ where a vegetative part is harvested. Magambo and Cannell (1981) attributed the low biomass production of tea to the continuous plucking of young shoots as yield because plucking reduced the size of the sink available for storage of assimilates. They showed that unplucked tea produced $36 \%$ more total biomass and 64\% more woody tissue than plucked tea. Furthermore, reduction of biomass production was greatest when the plucked shoot yield was highest, suggesting an inverse relationship between biomass production rate and tea yield. Tanton (1979) showed that allowing pluckable shoots to grow for a further one week (i.e. increasing the plucking round from 7 to $14 \mathrm{~d}$ ) they doubled their biomass. Therefore, plucking of young shoots at an early stage of their maturity reduces the sink capacity of the entire bush and reduces its biomass accumulation. However, shoots have to be 
plucked at this younger stage to maintain the quality characters of made tea (Watson, 1986a). Hence, Tanton (1979) suggests that tea yield improvement (in terms of quantity) should be possible by selecting for genotypes which are able to maintain superior quality characters in more mature shoots.

Radiation interception and efficiency of conversion: Biomass accumulation of a crop stand is the product between the amount of radiation intercepted and radiation-use efficiency, RUE (i.e. the amount of biomass produced per unit of radiation intercepted) (Monteith, 1977). Reported values of RUE for tea range from 0.25 -

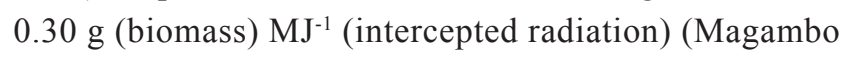
and Cannell, 1981; Squire, 1985) to $0.40-0.66 \mathrm{~g} \mathrm{MJ}^{-1}$ (Burgess and Carr, 1993, 1996a). All these values are much smaller than the typical RUE of $1.5 \mathrm{~g} \mathrm{MJ}^{-1}$ for herbaceous $\mathrm{C}_{3}$ crops growing with adequate water and nutrients. However, Burgess and Carr (1996a) argue that their RUE values are comparable to those reported for other woody crops such as oil palm [i.e. $0.70 \mathrm{~g} \mathrm{MJ}^{-1}$; Corley et al. (1971), Squire (1990)]. The restricted photosynthetic capacity (Mohotti et al., 2000; Mohotti and Lawlor, 2002) and reduction of potential biomass accumulation due to plucking of immature shoots are the probable reasons for the lower RUE of tea even when grown under optimum conditions. Furthermore, higher respiration rates of tea (Hadfield, 1974; Tanton, 1979; Barbora and Barua, 1988) could also contribute to the lower RUE and biomass production rates.

A fully-developed canopy of tea, which is maintained as a horizontal surface (i.e. 'plucking table') has been shown to intercept almost all incoming radiation. While Smith et al. (1993a) and De Costa et al. (unpublished results) observed up to $98 \%$ interception of radiation incident on the canopy, Burgess and Carr (1993) observed only up to $47 \%$ interception during their oneyear measurement period. However, here, the measurements had been made during a period when the crops were increasing their ground cover. Burgess and Carr (1996a) further observed that a 16-week drought treatment imposed two years after planting reduced the mean radiation interception by $25 \%$ and RUE by $78 \%$. Because of the elaborate branch structure of the tea bush, it is likely that an appreciable portion of radiation is also intercepted by the stems and branches. There have been no studies where radiation interception by leaves has been separated from that by the bush structure. This overestimation of radiation intercepted by leaves could also have contributed to the lower RUE values reported for tea.

Influence of canopy architecture: Canopy architecture determines the pattern of light distribution within a crop canopy and thereby influences the overall canopy photosynthesis and yield potential. There have been only a few studies where canopy architecture and its influence have been studied. In a tea bush which is maintained with a horizontal plucking table, canopy architecture is primarily determined by the leaf angle and the bush structure. It is generally known that the Chinatype genotypes of tea have a semi-erect leaf posture while the leaves of Assam-type are more horizontallyoriented. This is probably related to their origins, with semi-erect leaves of the China-types being necessary to reduce the interception of higher irradiance levels of the open habitats in which it originated. In contrast, the Assam-types which originated under shade had to develop a more horizontal leaf posture to intercept an adequate amount of radiation. The higher yielding ability of China-types have been attributed to their relatively erect leaf posture (Tanton, 1979) which allows greater light penetration into the canopy and reduces mutual shading of middle and lower leaves of the canopy. However, Tanton (1979) argues that the greater number of shoots per unit area in the erect-leaved types could be responsible for their higher leaf yield. It is possible that the higher number of shoots per unit area is a result of greater light penetration into the canopy. De Costa et al. (unpublished results) have also shown that a genotype having a numerically lower canopy light extinction coefficient (indicating relatively erect leaf posture) had a greater yield as compared to one having a higher extinction coefficient.

\section{SHOOT GROWTH}

Part of the biomass produced through radiation interception and conversion is partitioned into young shoots emerging on or just below the plucking table. However, as discussed in the previous section, the leaf yield of tea is determined to a greater extent by the 
number of shoots initiated rather than the amount of assimilates partitioned to an individual shoot. This section will focus on the process of shoot initiation and the external and internal factors controlling it.

The rate and duration of shoot initiation and expansion are directly related to four primary physiological processes: (a) initiation of shoots/leaves; (b) extension shoots and expansion of leaves; (c) production of assimilates; (d) partitioning of assimilates to shoots. All four of the above processes are influenced by two key environmental variables, namely $\mathrm{T}_{\mathrm{a}}$ and water availability. In addition, other environmental factors such as VPD of the air, intensity of incident solar radiation on the tea canopy, wind speed and soil temperature can influence one or more of the processes (Carr and Stephens, 1992).

Shoot growth in relation to plucking: The made tea is manufactured using tender shoots having few leaves with an apical bud. The harvest, therefore, mostly comprises shoots with 2-3 leaves. They can be either actively growing (i.e. with an active apical bud) or dormant (i.e. with a dormant apical bud). In addition, shoots with one leaf, mainly dormant shoots and shoots with more than three leaves are also included in the harvest. However, such shoots are not suitable for manufacture of good quality made tea. Hence, growers are encouraged to harvest more of actively growing shoots with 2-3 tender leaves. Ability to harvest such shoots depends to a greater extent on the rate of shoot growth and the size of shoot generations.

Shoot generations: The plucking table consists of a large number of shoots at different stages of growth ranging from growing axillary buds to harvestable shoots with 2-3 leaves. A group of shoots at the same stage of growth (generally identified by the number of leaves) is called a generation. The presence of shoot generations is the result of frequent harvesting of shoots at regular intervals and the shoot-to-shoot variation of rate of growth. Under regular and short plucking intervals (i.e. 7 d), different shoot generations are found in equal proportions (Wijeratne, 2001). However, this may not be true soon after a long stress period or after pruning or tipping, which usually synchronize bud break giving rise to just one or two generations. The number of generations also depends on plucking policies, mainly the frequency of plucking and methods of plucking (e.g. mechanical or manual harvesting). The number of generations can be as high as seven when bushes are plucked at short intervals (rounds) but less with extended plucking rounds and under mechanical harvesting systems. When the number of generations is more, a higher degree of selectivity is required to harvest shoots of the correct standard.

Of the shoot generations, older generations (i.e. active shoots with three or more leaves) are recognized as harvestable (pluckable) shoots while the other younger generations are known as arimbu. However, under any plucking policy, all dormant shoots are considered as pluckable shoots despite their size. When tea bushes are manually harvested one or two older generations are often harvested as flush shoots, leaving other younger generations for the following rounds. It is the presence of these shoot generations that ensures frequent harvesting under tropical climatic conditions. When the number of generations is less as observed in temperate tea growing countries such as Japan and China where shoot growth is restricted by temperature and moisture, the majority of shoots become harvestable at a particular time and, as a result, the whole crop for the year could be harvested in a few rounds during the warmer growing season.

Periodicity of shoot growth: Removal of tender apices of shoots by plucking removes the apical dominance which suppresses the growth of their axillary buds. Soon after the apical dominance is broken, one or two axillary buds below the point of plucking start swelling and regeneration of new shoots starts. Generally, the axillary bud immediately below the point of plucking is the first to produce a new shoot. The first leaf appendages to unfurl are the two outer covers of the bud as 'scale leaves' (Figure 4). These two scale leaves have a short lifetime and they fall off a few days after opening. The next leaf appendage to open is the 'fish leaf' which is an oval shaped, blunt leaf without apparent serration and veins. Some buds may produce two fish leaves. In this situation, the smaller one just above the scale leaves is termed small fish leaf or janum (Arunachalam, 1995) and the other as 
big fish leaf. After producing the fish leaf, the terminal bud produces normal flush leaves. The rate of growth of the axillary bud is very slow until it commences the production of normal leaves (Wijeratne, 2001). The terminal bud of a growing shoot on a frequently harvested tea bush produces several leaves before it ceases leaf production and becomes dormant. The dormant bud (banjhi or wangi) is a few millimetres long tiny bud usually covered by leaf hairs. It could be easily differentiated from an active terminal bud as the former is very small compared to the latter. The dormant apical bud re-activates its leaf production in the same order described above after the period of dormancy which could be several weeks or months depending on various ecological and genetic factors. This characteristic of alternative active and dormant phases of growth of a free growing shoot is known as periodic growth or growth periodicity of tea. Accordingly, a tea bush in plucking has both actively-growing and dormant shoots.

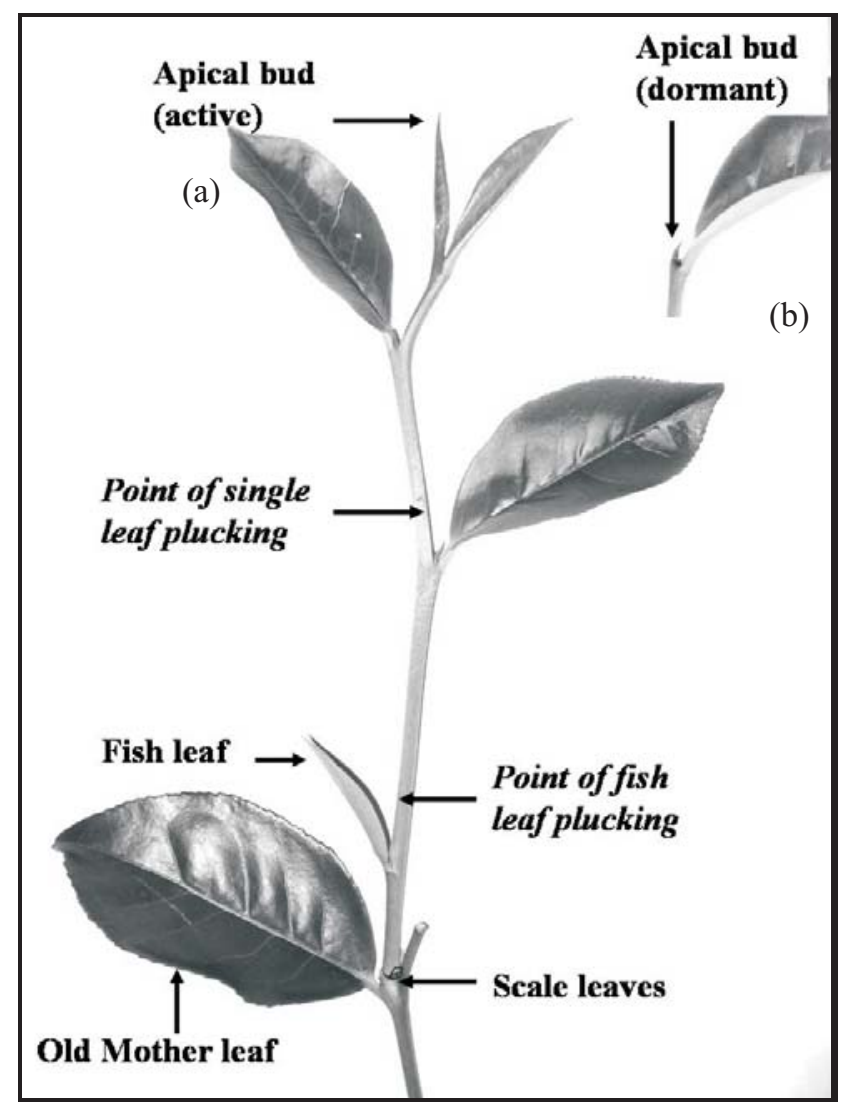

Figure 4. Typical active (a) and dormant (b) shoots of tea. (Source: Wijeratne, 2001).
Leaf initials (Primordia): Tea buds consist of several leaf initials or primordia, which are ready to open with the extension of internodes. Bond (1942) showed that there were 3-7 leaf primordia in an apical bud depending on its phase of growth (i.e. whether dormant or active). Barua and Das (1979) and Goodchild (1968) reported that the development of leaf primordia in a tea bud is a continuous process and occurred simultaneously with the unfurling of leaves.

Wijeratne (2001) reported that the number of leaf primordia in a terminal bud could vary from four to six. The dormant apical bud on its first exposure has only four primordia and the fully-grown active terminal bud contains six leaf initials. This led to the conclusion that when a bud becomes dormant, the development of leaf initials in an active apical bud ceases during the unfolding of the last two leaves on a tea shoot (Wijeratne, 1994). The axillary buds of an actively growing shoot had varying numbers of leaf initials, with the uppermost leaf axil having three primordia and the second or third leaf axils having five primordia. The older axillary buds below the third leaf from the apical bud consisted of a maximum of five leaf primordia. Nevertheless, depending on the size of fish and scale leaves, the number of primordia in the axillary buds of these leaf appendages varied from four to five. Wijeratne (2001) also reported that when a mature axillary bud with five leaf initials is released from apical dominance by plucking, it needs to develop three more leaf initials to attain bud break and open scale leaves. Therefore, an immature axillary bud with three leaf initials if exposed for re-growth by plucking will take a longer time for bud break than a mature bud with five leaf primordia as the former requires five additional primordia to be developed before bud break.

Dormancy of tea: Dormancy in tea is a temporary cessation of growth of a terminal bud. Although there is no apparent change in size or leaf production, the leaf initials are being developed inside the dormant bud and, hence, the tea bud does not have a truly dormant phase of growth (Bond 1942; Goodchild, 1968; Barua and Das, 1979). Bond (1945) reported that the vascular tissues, especially the xylem of the stem immediately below the apices of dormant shoots were poorly-developed. Although reasons for the formation of dormant buds in tea have not been clearly understood, it has been 
reported to be the result of either hormonal interaction (Pethiyagoda, 1964; Ahmed et al., 1965; Kulasegaram, 1967; Ranganathan et al., 1983) or lack of nutrient supply to actively growing apices (Bond, 1945). Further, observations have shown that the stage in the pruning cycle, temperature, depletion of food reserves (Ranganathan et al., 1983), types and levels of fertilizers (Kulasegaram, 1967) and clonal characteristics (Nathaniel, 1976; Stephens and Carr, 1990) have significant influence on the formation of dormant buds. Photoperiod also influences the onset and release of bud dormancy (Matthews and Stephens, 1998b). Tanton (1982a) found increased formation of dormant shoots in tea bushes under low ambient temperature and shorter day lengths. Further, shoots that originate from deep in the canopy, often known as secondary shoots, are more likely to become dormant when only a few leaves have unfolded. Similarly slow growing shoots are also likely to turn dormant sooner than fast growing ones (Carr, 2000). Field observations have shown that the density of dormant shoots are less during periods of higher leaf yield (rush crop) and high during periods of lower leaf yield (Wijeratne, 1994).

Although actively growing tea shoots on a harvested bush become dormant after producing 3-4 leaves, most of the new shoots growing after pruning do not show a clear periodic growth at shorter intervals as observed on a tea bush in plucking. Carr (2000) also reported that shoots of pruned tea bushes produce more leaves before they become dormant. This could be attributed to less competition between shoots for nutrient and water and also the presence of growth hormones in adequate concentrations. However, the density (i.e. number per bush per unit area) of such shoots is remarkably less than that of a tea bush in plucking.

Weight of shoot differs depending on the phase of shoot growth (i.e. whether active or dormant). Wijeratne (1994) reported that a tea shoot with an active terminal bud weighs $10-18 \%$ more than a shoot with a dormant bud having the same number of leaves. The presence of dormant shoots reduces the productivity and quality of tea. However, such disadvantages can be minimized by adopting correct plucking policies so that majority of shoots are harvested before they attain dormancy. However, some investigations have shown that the formation of dormant buds has no significant influence on the tea yield (Pethiyagoda, 1964; Tanton, 1981). Furthermore, assimilates are mostly diverted to roots during low-yielding periods with more dormant shoots. Hence, a rhythmic pattern of shoot growth enables the bush to maintain a balanced growth between shoot and root (Carr, 1970; Fordham, 1972; Tanton, 1981; Manivel and Hussain, 1982; Kulasegaram and Kathiravetpillai, 1983). Studies have shown that drought tolerant clones produce more dormant shoots than drought susceptible clones and that more shoots become dormant during periods of water stress. Further, variation of the density of dormant shoots occurs in a cyclic pattern with a higher density corresponding to the lean cropping months (Wijeratne, 2001). Formation of dormant shoots reduces production of transpiring leaves and fast growing apices, thus reducing the water requirement for growth. Hence, greater production of dormant shoots can be considered as a useful mechanism of drought tolerance (Odhiambo et al., 1993).

\section{FACTORS AFFECTING SHOOT GROWTH}

Growth of tea shoots, like in many other plants is greatly influenced by external environmental factors and genetic factors. The rate of shoot growth, usually measured as shoot extension rate (SER), largely governs the harvestable shoot density (i.e. $\mathrm{N}_{\mathrm{sh}}$ ) and $\mathrm{W}_{\mathrm{sh}}$ and hence, the yield. Of the environmental factors, $T_{a}$, VPD and soil water availability are the major determinants of shoot growth in many of the tea growing regions of the world.

\section{Effects of environmental factors}

Temperature: Generally, tea grows well within a $\mathrm{T}_{\mathrm{a}}$ range of about $18-25^{\circ} \mathrm{C}$. Air temperatures below $13^{\circ} \mathrm{C}$ and above $30^{\circ} \mathrm{C}$ have been found to reduce shoot growth (Carr, 1972; Watson, 1986b; Carr and Stephens, 1992). The rate of shoot initiation in tea increases linearly with rise in temperature from the base (threshold) temperature $\left(\mathrm{T}_{\mathrm{b}}\right)$ to an optimum temperature $\left(\mathrm{T}_{\mathrm{o}}\right)$ and thereafter decreases linearly with further increases in temperature up to the maximum or ceiling temperature $\left(\mathrm{T}_{\mathrm{ce}}\right)$ (Squire, 1990; Roberts et al., 1997). The $\mathrm{T}_{\mathrm{b}}$ for tea shoot extension has been found to vary from $7^{\circ} \mathrm{C}$ (Obaga et al., 1988) to about $15^{\circ} \mathrm{C}$ (Stephens and Carr, 1990 ), with $12.5^{\circ} \mathrm{C}$ being the average (Carr and Stephens, 1992). Stephens and Carr 
(1993) showed that $\mathrm{T}_{\mathrm{b}}$ for shoot extension (i.e. $10^{\circ} \mathrm{C}$ ) of tea growing with adequate water and nutrients was $2-3^{\circ} \mathrm{C}$ higher than that for shoot development (i.e. initiation). In contrast, Squire et al. (1993) observed similar $T_{b}$ for both these processes in tea growing in the Kenyan highlands. However, the work of Squire et al. (1993) covered a temperature range of only $2^{\circ} \mathrm{C}$ while Stephens and Carr (1993) covered a range of $5^{\circ} \mathrm{C}$. Moreover, Stephens and Carr (1990) observed a greater $\mathrm{T}_{\mathrm{b}}$ for shoot extension during a warming phase (i.e. $15^{\circ} \mathrm{C}$ ) than during a cooling phase $\left(13^{\circ} \mathrm{C}\right)$.

Although $\mathrm{T}_{\mathrm{o}}$ for shoot growth of tea has not been clearly defined, Carr (1972) reported the $\mathrm{T}_{\mathrm{o}}$ for growth of tea to be in the range between $18-30^{\circ} \mathrm{C}$ and $\mathrm{T}_{\mathrm{ce}}$ to be in the range $35-40^{\circ} \mathrm{C}$. However, Tanton (1992) implied that the upper temperature limit for shoot growth could be as high as $36^{\circ} \mathrm{C}$ in the absence of other stress factors limiting shoot growth. Wijeratne and Fordham (1996) reported that shoot extension rate and weight per shoot decreased when $\mathrm{T}_{\mathrm{a}}$ rose above $26^{\circ} \mathrm{C}$. Shoot population density also decreased linearly above a $\mathrm{T}_{\mathrm{a}}$ range of $25.5-29^{\circ} \mathrm{C}$.

A growing tea bud needs to accumulate about $150^{\circ} \mathrm{C}$ days above $\mathrm{a}_{\mathrm{b}}$ of $12.5^{\circ} \mathrm{C}$ to unfurl a leaf and $450-500^{\circ} \mathrm{C}$ days to produce a harvestable tea shoot (Squire, 1990). The concept of thermal duration (degrees-days) helps tea growers to determine important plucking policies such as plucking rounds for different periods of the year based on their temperature variation. Accuracy of such predictions depends to a large extent on the precision of the estimation of $\mathrm{T}_{\mathrm{b}}$ and the absence of other limiting factors for growth such as soil water - and VPD. Carr (2000) also reported that small differences in $T_{b}$ can have relatively large effects on rate of shoot development and extension at high altitudes where $\mathrm{T}_{\mathrm{a}}$ is low.

The other practical implication limiting the use of the thermal duration concept for deciding plucking rounds is the presence of a mixture of genotypes in a given tea plantation as $T_{b}$ may vary between genotypes. It has been shown that under tropical weather conditions, $\mathrm{T}_{\mathrm{a}}$ sometimes rises above $\mathrm{T}_{0}$. In such situations, a thermal duration calculation using uncorrected $\mathrm{T}_{\mathrm{a}}$ would overestimate the thermal time requirement. Therefore, accurate estimation of $\mathrm{T}_{\mathrm{o}}$ also becomes crucial. Further, Wijeratne (2001) reported that the thermal duration requirement of the cultivar TRI2025 for producing a harvestable tea shoot (three leaves and a bud) in Sri
Lanka varied from $330-370^{\circ} \mathrm{C}$-days at high elevation to $500-600^{\circ} \mathrm{C}$-days at low elevation. The thermal duration for initiation of one leaf (i.e. phyllochron) was estimated to be $30-40^{\circ} \mathrm{C}$-days and $60-70^{\circ} \mathrm{C}$-days at the same two elevations respectively. In addition to the phyllochron, the plastochron of tea (i.e. the duration for initiation of one leaf primordium) is also influenced by temperature. Wijeratne (1994) found at lower elevations in Sri Lanka that increasing $\mathrm{T}_{\mathrm{a}}$ above $25^{\circ} \mathrm{C}$ increases the plastochron. Moreover, the minimum temperature accumulation for producing a tea shoot of harvestable size in Kenya has been estimated to be $108-212^{\circ} \mathrm{C}$-days. These findings cast doubt about the possibility of using a universal $\mathrm{T}_{\mathrm{b}}$ in estimating the thermal time requirement. Therefore, such variations need to be carefully considered and necessary corrections included in the temperature response model before any the predictions are made (Wijeratne, 1994).

An important parameter that illustrates the influence of $\mathrm{T}_{\mathrm{a}}$ on shoot initiation and extension is the "shoot replacement cycle (SRC)', which is the time required for an axillary bud released from apical dominance (when a shoot is plucked) to develop three leaves and a terminal bud. Stephens and Carr (1993) showed that SRC of fullyirrigated and well-fertilized tea increased from $65 \mathrm{~d}$ during the warm wet season in Tanzania to $95 \mathrm{~d}$ during the cool dry season. The temperature difference between these two seasons represented a $5^{\circ} \mathrm{C}$ range. The unirrigated and unfertilized tea also showed an extension of SRC from 75 to $180 \mathrm{~d}$.

Because of the decline of $\mathrm{T}_{\mathrm{a}}$ with rising altitude, there is an apparent variation in the rate of shoot growth of tea depending on the altitude where it is grown (Squire, 1990; Squire et al., 1993; Balasooriya, 1996). Squire et al. (1993) showed that the duration of the shoot growth cycle increased, but the SER decreased with increasing altitude (and decreasing $\mathrm{T}_{\mathrm{a}}$ ) in Kenya. Furthermore, there was a cultivar difference in the magnitudes of the above responses indicating cultivar variation in temperature sensitivity. Interestingly, the temperature-insensitive cultivar did not show a significant linear regression between SER and $\mathrm{T}_{\mathrm{a}}$, while the temperature-sensitive cultivar did. Although $\mathrm{W}_{\text {sh }}$ showed a significant cultivar variation, it was stable across altitudes within each cultivar. The yield response of the two tested cultivars to increasing altitude differed as a result of this variable response of SER and length of the shoot growth cycle. 
The yield of a temperature-sensitive cultivar decreased significantly with increasing altitude while that of the other temperature-insensitive cultivar remained stable until an altitude of $2120 \mathrm{~m}$ was exceeded. Smith et al. (1993b) also showed large cultivar differences in the response of exponential relative shoot extension rate to $\mathrm{T}_{\mathrm{a}}$ within the range of $18-23^{\circ} \mathrm{C}$.

In addition, some tea growing regions experience both cooler and warmer climates at a given altitude. Under such conditions, during cooler periods with little - or no active shoot growth, carbohydrates are mostly partitioned to roots. During subsequent warmer periods, these carbohydrates are retranslocated to the developing shoots (Fordham, 1972; Rahman and Dutta, 1988; Squire, 1977). Hence, temperature modifies the balance between shoot and root growth by influencing the physiology of shoot growth.

In addition to $T_{a}$, soil temperature $\left(T_{s}\right)$ also influences the growth of the tea plant (Carr, 1970, 1972; Carr and Stephens, 1992), especially in situations where growth of tea is limited by low $\mathrm{T}_{\mathrm{s}}$. Magambo and Othieno (1983) reported that high $\mathrm{T}_{\mathrm{s}}$ during the day time combined with low $\mathrm{T}_{\mathrm{s}}$ during the night induced early flowering of tea and reduced its vegetative growth. Othieno (1982) showed that the diurnal variation of $T_{s}$ in a young tea field with incomplete canopy cover (i.e. $<60 \%$ ) differed under different types of mulches depending on their heat absorptivity. However, these variations disappeared when the canopy cover of tea increased above $60 \%$. Othieno and Ahn (1980) and Tanton (1992) also reported a close relationship between $T_{s}$ and yields of young tea. The mulches that allowed higher $\mathrm{T}_{\mathrm{s}}$ levels showed higher tea yields (Othieno, 1982).

Water stress: Shoot growth of tea is influenced by water deficits in both the soil (soil water deficits, SWD) and the aerial environment (air VPD). Reduction of shoot extension, leaf area expansion, stem diameter, internode elongation and number of lateral branches of woody plants including tea, have been reported to be associated with SWD (Fordham, 1969; Carr, 2000). Stephens and Carr (1993) showed that the length of a pluckable shoot with three leaves and a bud during the dry season of Tanzania was reduced from $130 \mathrm{~mm}$ in fully-irrigated and wellfertilized tea to $15 \mathrm{~mm}$ in unirrigated and unfertilized tea. Due to slow growth of shoots under soil water stress tea yields are greatly reduced. This slow growth under environmental stress is a result of low shoot $\psi_{\mathrm{w}}$ that affects cellular turgor (Carr and Stephens, 1992; Squire, 1977). However, Carr (2000) reported that although water stress reduces shoot length at harvest and decreases dry matter content it has little effect on $\mathrm{N}_{\mathrm{sh}}$. In many teagrowing regions, seasonal fluctuation in tea yield has been related to the soil moisture level. Water stress delays or stops bud break leading to accumulation of dormant buds in the tea bush. These buds start growing simultaneously (synchronized bud break) with rain, thus forming a peak in the crop (rush crop) known as "Fordham peak". When all the fast growing vigorous shoots are harvested within the peak cropping period, a subsequent trough in production occurs due to the absence of pluckable shoots (Fordham, 1970; Fordham and Palmer-Jones, 1977).

In addition to the SWD, high ambient VPD also reduces shoot growth of tea even when the soil is irrigated. The critical VPD affecting growth of tea shoots has been reported to be about 2-2.3 $\mathrm{kPa}$ (Hoshina et al., 1983; Squire, 1979; Carr and Stephens, 1992; Tanton, 1992). However, in the warmer low altitudes $(<600 \mathrm{~m})$ of Sri Lanka, shoot growth has been affected at lower VPD of less than $1.2 \mathrm{kPa}$ (Wijeratne and Fordham, 1996). Usually shoot extension is less sensitive to dry weather than leaf expansion. Effects of water stress on shoot growth and yield are further discussed elsewhere in this paper.

Photoperiod: Shoot growth of tea is also affected by photoperiod. Investigations have shown that the growth of tea shoots is depressed when the photoperiod is less than about $11 \mathrm{~h}$ especially when combined with warm $\left(20^{\circ} \mathrm{C}\right)$ nights (Fordham 1970; Herd and Squire, 1976; Tanton 1982a). In addition, Barua (1969) found that there is a greater tendency for tea shoots to become dormant when the photoperiod is less than $11.16 \mathrm{~h}$. Because of this influence of photoperiod on the onset and release of bud dormancy (and therefore the number of actively growing shoots at any given time), Matthews and Stephens (1998b) predicted that tea yields could be sensitive to the critical photoperiods (Roberts et al., 1997) for controlling bud dormancy and shoot development. However, such influences may not have a significant impact on shoot growth or yield under tropical weather conditions where the photoperiod is usually greater than the critical value. 


\section{WATER RELATIONS}

The water status of a tea plant is determined by the balance between water absorption by its root system and water loss through transpiration. The amount of water absorbed is mainly determined by the maximum rooting depth and the water available within the root zone. Tea is generally considered to be a shallow-rooting plant, sensitive to the physical condition of the soil (Harler, 1964). Although seedling tea has a tap root which has been reported to penetrate as deep as $4.5 \mathrm{~m}$ (Carr, 1971a, 1972), a major portion of the root system of clonal tea is located within the first $30 \mathrm{~cm}$ of the soil profile (De Costa and Surenthran, 2005). Nixon and Sanga (1995) also observed that the weight of fine roots with diameters less than $1 \mathrm{~mm}$ decreased exponentially with increasing soil depth. However, Carr (1977a) has observed root systems as deep as $3 \mathrm{~m}$ in clones, while Stephens and Carr (1991b) have observed a maximum rooting depth of $5.5 \mathrm{~m}$. Carr (1977b) showed that during the gradual development of a drought, clonal tea develops water stress earlier than seedling tea. This was partly attributed to the variation in their root systems. Earlier development of water stress was indicated by the faster decline of shoot xylem $\psi_{\mathrm{w}}$ and earlier stomatal closure. However, the results of Carr (1977a) suggested that seedlings were more susceptible to extreme dry conditions (i.e. a potential soil water deficit of $300 \mathrm{~mm} \mathrm{~m}^{-1}$ of soil depth, representing a $50 \%$ loss of available water) than clonal tea, which had deep root systems. In another study carried out over all different tea growing agroclimatic regions of Sri Lanka, the seedlings had a significantly deeper root system than clones. Moreover, clones exhibited a significantly deeper active root zone comprising of more feeder roots than seedlings (Mohotti, unpublished results). However, in a similar study carried out using five-year-old, field-grown comparison trial of different seedling progenies and clones (TRI 2023 and a known drought tolerant clone, $\mathrm{DN})$, the overall mean root depth was higher in clones than in seedlings (Liyanapatabendi et al., 2007). The overall root growth of the clone DN was superior to all other seedling progenies and the clone TRI 2023. The clones had a significantly deeper active root zone comprising of more feeder roots. Therefore, depth of the root system probably has a greater influence in determining the drought tolerance of a given genotype than its method of propagation (i.e. whether seedling or clonal).

Mohotti et al. (2003b) have shown that organicallymanaged tea has a greater proportion of its root system in deeper layers of the soil profile as compared to tea managed conventionally where inorganic fertilizer applied to the soil surface along with other recommended management practices. There were associated changes in the anatomy of roots of 1-2 mm diameter with organicallygrown tea having significantly thicker cork layers, smaller xylem vessel diameters and xylem wall diameters (Mohotti et al., 2003c). Sap flow studies by Mohotti et al. (unpublished results) have shown that organicallygrown tea also had higher WUE compared to conventionally-grown tea.

Transpiration: Water use of tea and its controlling factors have been studied extensively (Dagg, 1970; Willat, 1971, 1973; Carr, 1974; Cooper, 1979; Callander and Woodhead, 1981; Carr, 1985; Stephens and Carr, 1991b; Anandacoomaraswamy et al., 2000; Kigalu, 2007). However, water use (or evapotranspiration) include both transpiration from the foliage canopy and soil evaporation. A well-maintained tea canopy covers the ground almost completely allowing very little solar radiation to penetrate down to the soil surface. In such situations, evapotranspiration is almost equal to transpiration. There are only a few studies where direct measurements of transpiration have been done in tea over prolonged periods. In one such study, Anandacoomaraswamy et al. (2000) showed that both hourly and daily transpiration rates were highly sensitive to soil water availability. Daily transpiration rate was maintained at a maximum of $1.6 \mathrm{~L} \mathrm{plant}^{-1} \mathrm{~d}^{-1}$ when the soil water content (SWC) decreased from field capacity ( $44 \%$ $\mathrm{v} / \mathrm{v}$ ) down to $33 \%$. Within this range of SWC, maximum hourly transpiration rates of 0.53-0.93 $\mathrm{L} \mathrm{plant}^{-1} \mathrm{~h}^{-1}$ were maintained during the period between 1000 and $1500 \mathrm{~h}$. When the SWC decreased below 33\%, daily and hourly transpiration rates declined rapidly down to $0.71 \mathrm{~L} \mathrm{plant}^{-1}$ $\mathrm{d}^{-1}$ and $0.27-0.53 \mathrm{~L}_{\text {plant }}{ }^{-1} \mathrm{~h}^{-1}$ respectively near permanent wilting point $(15 \%)$. In this instance, the reduction of transpiration rate with decreasing SWC was probably caused by gradual stomatal closure and consequent reduction of $g_{s}$. 
Control of transpiration by $g_{s}$ and shoot $\psi_{w}$ : Tea has highly sensitive stomata, which show partial closure during midday even when the plants are growing on a wet soil (Williams, 1971; Carr, 1977a). Stomatal closure was slightly preceded by reduced shoot xylem $\psi_{\mathrm{w}}$, indicating that stomatal closure occurred as a response to an internal water deficit in the shoot. This indicates that the rate of root water absorption and its subsequent transfer through the xylem is not very efficient in tea even under conditions of moderate atmospheric demand (i.e. $>5 \mathrm{~mm}$ $\left.\mathrm{d}^{-1}\right)$. This could be due to specific characteristics in the absorbing region of the root system and/or the xylem vessels.

On a relatively wet soil, shoot $\psi_{\mathrm{w}}$ recovered during late afternoon along with increased $g_{s}$. In contrast, when SWD was significant, shoot $\psi_{\mathrm{w}}$ did not recover even by late afternoon. However, even when shoot $\psi_{\mathrm{w}}$ was still as low as $-1.8 \mathrm{MPa}$, stomata showed some re-opening under cloudy conditions, indicating a stomatal response which was independent from shoot $\psi_{w}$. This stomatal reopening was probably a response to decreasing VPD in the surrounding air in late afternoon under cloudy conditions. Stomatal movement is one of several important physiological processes, which respond to VPD. In fact, Carr (1977a) showed that both $g_{\mathrm{s}}$ (measured indirectly as liquid infiltration score) and shoot $\psi_{\mathrm{w}}$ were negatively correlated with VPD, $\mathrm{T}_{\mathrm{a}}$ and incident solar radiation intensity. Interestingly, Carr (1977a) found that shoot $\psi_{\mathrm{w}}$ (and thereby $g_{\mathrm{s}}$ ) of tea was more sensitive to $\mathrm{T}_{\mathrm{a}}$ and VPD when the soil was wet than when it was dry. This was probably because higher $T_{a}$ and VPD caused greater transpiration rates, which in turn, would have lowered shoot $\psi_{\mathrm{w}}$ even when tea is grown on a wet soil. In contrast, on a dry soil, early stomatal closure would have prevented transpiration from responding to higher $\mathrm{T}_{\mathrm{a}}$ and VPD, making shoot xylem $\psi_{\mathrm{w}}$ less sensitive to atmospheric water stress. Squire (1978) also observed that $g_{s}$ of tea growing in Malawi was principally determined by irradiance, except during the dry months. During the wet period, $g_{\mathrm{s}}$ was independent of shoot $\psi_{\mathrm{w}}$, VPD and $\mathrm{P}_{\mathrm{n}}$. In contrast, during the dry season, $g_{\mathrm{s}}$ remained unaffected by $\psi_{\mathrm{w}}$ and VPD, but was more closely related to $\mathrm{P}_{\mathrm{n}}$.

The observation that shoot $\psi_{\mathrm{w}}$ and $g_{\mathrm{s}}$ of tea is less sensitive to $T_{a}$ and VPD in a dry soil provides indirect evidence that stomatal opening of tea may be controlled by hormonal signals originating from roots (Zhang et al., 1987; Davies and Zhang, 1991). Callander and Woodhead (1981) observed that the canopy conductance per unit leaf area of tea was little affected by soil water deficits as large as $370 \mathrm{~mm}$. This was attributed to the deep root system of tea. The wet season canopy conductance was $12 \%$ higher than for a dry season canopy, receiving the same net irradiance and VPD. This observation also indicates greater stomatal opening when the soil is wet and provides further evidence for hormonal signals from roots controlling the stomata of tea.

Stomatal dynamics and drought resistance of tea: Carr (1977a) observed a clear linear relationship between shoot $\psi_{\mathrm{w}}$ and $\mathrm{g}_{\mathrm{s}}$, showing the close mechanistic link between shoot water status and stomatal opening. Importantly, the slope of this relationship, which is a measurement of the sensitivity of stomata to water stress, differed for different genotypes (including both seedlings and clones). Furthermore, $x$-axis intercept of the above relationship (i.e. shoot $\psi_{\mathrm{w}}$ at zero $g_{\mathrm{s}}$ ) showed significant variation between genotypes. Carr (1977a) showed that both the slope and $\mathrm{x}$-axis intercept were related to drought resistance of a given genotype of tea, with relatively resistant genotypes showing a lower slope (i.e. indicating stomata which are less sensitive to water stress) and a lower $\mathrm{x}$-axis intercept (i.e. complete stomatal closure occurring at a lower shoot $\psi_{\mathrm{w}}$ ). In addition, Carr (1977a) also showed that different tea genotypes can be screened for their drought resistance on the basis of the $y$-axis intercept of the above relationship, which indicates the maximum $g_{\mathrm{s}}$ at shoot $\psi_{\mathrm{x}}=0$ (i.e. shoot tissue at full saturation). The ratio between the respective $g_{\mathrm{s}}$ at a specified level of water stress (e.g. $\psi_{\mathrm{w}}=-1.5 \mathrm{MPa}$ ) and at $\psi_{\mathrm{w}}=0$, was higher in relatively drought resistant genotypes and decreased in genotypes with increasing drought susceptibility.

In a separate study, Carr (1977b) identified two possible mechanisms/pathways of stomatal response to increasing drought. Some clones had highly sensitive stomata, which closed earlier during a drying cycle and thereby conserved water by reducing transpiration. This mechanism was demonstrated by Wijeratne et al. (1998a) in a relatively drought-tolerant Sri Lankan genotype TRI 2025. Moreover, the critical leaf $\psi_{w}$ for significantly reducing $g_{\mathrm{s}}$ and transpiration rate was higher for TRI 2025 
$(-0.65 \mathrm{MPa})$ than for a drought-susceptible genotype TRI 2023 (-0.85 MPa) (Wijeratne et al., 1998b). Over a diurnal drying cycle, the drought-susceptible genotype transpired at a higher rate over a longer period than the drought-tolerant genotype. Consequently, the droughttolerant genotype maintained a higher leaf $\psi_{w}$ and leaf relative water content (RWC). The rate of transpiration and the consequent rate of reduction of leaf $\psi_{w}$ with increasing VPD were greater in the drought-susceptible genotype. Greater stomatal densities of the droughtsusceptible genotype (Wadasinghe and Wijeratne, 1989) contributed to its higher transpiration rates. In a study comparing the water relations of three genotypes of tea, Sandanam et al. (1981) also showed that the most drought tolerant genotype (DN) had the highest leaf diffusive resistance under water stress.

In contrast, some clones were able to keep their stomata open for a longer period during a drought and thereby maintain higher transpiration rates. However, there was no appreciable reduction in shoot $\psi_{w}$. Hence, it is likely that such clones probably had a deeper root system and thereby had a greater water absorption capacity. This strategy of keeping the stomata open for a longer period during a drought would probably allow greater uptake of $\mathrm{CO}_{2}$ and higher $\mathrm{P}_{\mathrm{n}}$ and probably greater $\mathrm{W}_{\mathrm{sh}}$. However, such a strategy would only be possible in deep soils with a higher water storage capacity. It could be a high risk strategy on shallow soils, on which a considerable portion of tea is grown in some countries (e.g. Sri Lanka).

Osmotic adjustment also enables a given genotype of tea to keep its stomata open for a longer period during a drought. Wijeratne (1994) and Karunaratne et al. (1999) have shown that a relatively drought resistant genotype had a greater capability for osmotic adjustment than a relatively drought susceptible genotype. Analysis of measured pressure-volume curves (Wijeratne et al., 1998 b) showed that the drought-tolerant genotype had a lower osmotic potential $\left(\psi_{\mathrm{s}}\right)$ at full turgor and a higher apoplastic water content than the drought-susceptible genotype. The lower $\psi_{\mathrm{s}}$ at full turgor provides evidence for osmotic adjustment through active accumulation of solutes in the leaves during drought stress. The lower $\psi_{\text {s }}$ also allows the drought-tolerant genotype to absorb water from drier soils because of the greater $\psi_{w}$ gradient between soil and plant. This was confirmed by the lower soil water content and soil $\psi_{w}$ at permanent wilting point of the drought-tolerant genotype. Furthermore, the higher apoplastic water content also allows a plant to better tolerate drought by transferring apoplastic water to the cytoplasm during periods of water deficits. Sandanam et al. (1981) also showed significant genotypic variation in the pressure-volume curves of both young and old leaves of tea. At a given leaf $\psi_{w}$, the leaf RWC was higher in drought-tolerant genotypes than in droughtsusceptible genotypes. These results show that both stomatal control and osmotic adjustment contribute to drought tolerance of tea.

\section{Environmental factors controlling transpiration of tea}

Incident radiation and shade: When the soil is at or near saturation, solar radiation intensity is the main determinant of transpiration as it provides the latent heat energy required for evaporation of water. Anandacoomaraswamy et al. (2000) observed that transpiration rate of field-grown mature tea decreased linearly with decreasing irradiance from full sunlight until $15 \%$ of full sunlight at the rate of $0.031 \mathrm{~L} \mathrm{plant}^{-1} \mathrm{~d}^{-1}$ for each $1 \%$ reduction of solar irradiance. Shade also reduces transpiration rate primarily by decreasing the irradiance incident on the tea canopy and by reducing canopy temperature $\left(\mathrm{T}_{\mathrm{c}}\right)$. Tea growing under the shade of Grevillea robusta had substantially lower transpiration rates $\left(0.42-1.071 \mathrm{~L}_{\text {plant }} \mathrm{d}^{-1}\right)$ than unshaded tea $(3.511 \mathrm{~L}$ plant $^{-1} \mathrm{~d}^{-1}$ ) (Anadacoomaraswamy et al., 2000). Some of the antitranspirants also reduced transpiration by reducing the energy load on the foliage canopy of tea. For example, Anandacoomaraswamy et al. (2000) showed that the antitranspirant, Kaolin, increased the reflectance of incident radiation from leaves and reduced $\mathrm{T}_{\mathrm{c}}$ by $2-4^{\circ} \mathrm{C}$, thereby reducing transpiration rate, especially during the midday.

Wind and shelter: Some of the tea-growing regions, especially at high altitudes, experience periods of high wind speeds during certain times of the year. High wind speeds generally tend to increase transpiration rates from extensive tea canopies and thereby accelerate the development of soil water deficits during dry periods. To counter these adverse effects of high wind speeds, wind breaks and shelter belts of different tree species are grown. However, contrary to these expectations, Carr 
(1971b, 1985) showed that tea sheltered from winds by shelter belts ( $4 \mathrm{~m}$ tall Hakea saligna) can have higher transpiration rates than unsheltered tea and thereby experience water stress as indicated by lower leaf $\psi_{\mathrm{w}}, g_{\mathrm{s}}$ and higher SWD during periods of dry weather. This can be explained by basic physical principles (Carr, 1985). Reduction of wind speed by shelter increases the aerodynamic resistance $\left(r_{\mathrm{a}}\right)$ of the tea canopy. This increases day-time $\mathrm{T}_{\mathrm{c}}$ (by $1-2^{\circ} \mathrm{C}$ ) because of the greater resistance to heat transfer from the canopy to the surrounding air. Although Carr (1985) observed a higher canopy resistance $\left(r_{\mathrm{c}}\right)$ in sheltered tea as compared to the unsheltered, the greater $\mathrm{T}_{c}$ under shelter can induce higher transpiration rates (because of greater leaf-air VPD) and reduce leaf $\psi_{w}$, especially during dry periods. On the other hand, during rainy periods, greater soil water availability allowed sheltered tea to maintain higher transpiration rates without reducing leaf $\psi_{\mathrm{w}}$. Moreover, during the rainy periods, the higher $T_{c}$ and leaf $\psi_{w}$ values of sheltered tea allowed it to produce a greater yield than unsheltered tea by increasing the rates of shoot initiation and extension. Therefore, Carr (1985) concluded that shelter is beneficial for tea growing under the following conditions: (a) in cooler regions where $\mathrm{T}_{\mathrm{a}}$ is closer to the $\mathrm{T}_{\mathrm{b}}$ for shoot growth; (b) under irrigation; and (c) in areas with significant advection of hot dry air on to tea fields from the surrounding areas.

Transpiration efficiency and water use efficiency: Transpiration efficiency $\left(\mathrm{T}_{\mathrm{E}}\right)$ of tea can be computed on the basis of the weight of made tea per unit of water transpired. Anandacoomaraswamy et al. (2000) obtained a $T_{E}$ of $9.637 \mathrm{~kg} \mathrm{ha}^{-1}$ (made tea) $\mathrm{mm}^{-1}$ of water transpired for field-grown clonal tea in Sri Lanka. Stephens and Carr (1991b) obtained WUE values, estimated as the slope of the linear regression between made tea yield and evapotranspiration, ranging from 1.5 to $5.2 \mathrm{~kg} \mathrm{ha}^{-1} \mathrm{~mm}^{-1}$ for clonal tea in Tanzania. These are lower than the $T_{E}$ value obtained by Anandacoomaraswamy et al. (2000), probably because the water use estimate of Stephens and Carr (1991b) incorporated both soil evaporation and transpiration. Although $\mathrm{T}_{\mathrm{a}}$ of both sites was similar, the VPD in the Sri Lankan site (daily mean ranging from 0.52$0.88 \mathrm{kPa}$ ) was probably lower than that in the Tanzanian site (not exceeding $2 \mathrm{kPa}$ ). Although Stephens and Carr (1991a) contend that the VPD was unlikely to have restricted shoot growth, it is possible that the slightly greater VPD in their study may have increased evapotranspiration and thereby reduced $\mathrm{T}_{\mathrm{E}}$ and WUE. This reduction of $T_{E}$ with increasing VPD is in agreement with the theoretical analyses of Bierhuizen and Slatyer (1965) and Monteith (1986).

Stephens and Carr (1991b) further showed that WUE of tea is influenced by water availability, nitrogen application and season. During a 'warm' (daily mean $\mathrm{T}_{\mathrm{a}}$ increasing from $16-18^{\circ} \mathrm{C}$ up to $22-24^{\circ} \mathrm{C}$ ) dry season, WUE increased from $0.6-1.0 \mathrm{~kg} \mathrm{ha}^{-1} \mathrm{~mm}^{-1}$ under rainfed conditions up to $2.2-4.1 \mathrm{~kg} \mathrm{ha}^{-1} \mathrm{~mm}^{-1}$ under irrigated conditions. The response of WUE to irrigation increased with increasing nitrogen fertilizer application up to $225 \mathrm{~kg}$ $\mathrm{N} \mathrm{ha}^{-1}$. In contrast, during a 'cool' (daily mean $\mathrm{T}_{\mathrm{a}}$ around $14^{\circ} \mathrm{C}$ ) dry season, WUE did not respond significantly to irrigation, irrespective of the level of fertilizer application. However, as compared to the warm dry season, in the cool dry season, WUE showed a greater response to nitrogen fertilizer application up to $375 \mathrm{~kg} \mathrm{~N} \mathrm{ha}^{-1}$. At any given irrigation $x$ fertilizer treatment combination, WUE in the warm dry season was greater than that in the cool dry season. This could be a positive response to the higher $\mathrm{T}_{\mathrm{a}}$ in the warm dry season as $\mathrm{T}_{\mathrm{a}}$ in the cool dry season was closer to the $\mathrm{T}_{\mathrm{b}}$ for shoot extension, i.e. $12-15^{\circ} \mathrm{C}$ (Tanton, 1982b; Stephens and Carr, 1990). When averaged across seasons and irrigation treatments, WUE of tea increased with increasing nitrogen fertilizer application, from 1.5-2.6 $\mathrm{kg} \mathrm{ha}^{-1} \mathrm{~mm}^{-1}$ in unfertilized tea to $3.3-5.2 \mathrm{~kg} \mathrm{ha}^{-1} \mathrm{~mm}^{-1}$ in tea fertilized at $225 \mathrm{~kg} \mathrm{~N} \mathrm{ha}^{-1}$.

The above-mentioned results of Stephens and Carr (1990) show interesting insights into the physiological basis of the determination of WUE in tea. As WUE is the amount of yield produced per unit of water used through evapotranspsiration, it could be affected by factors influencing shoot growth and water use. At lower $\mathrm{T}_{\mathrm{a}}$ (e.g. cool dry season), WUE responds more to nitrogen fertilizer than to irrigation. This could probably be because under cooler conditions, nitrogen availability through absorption, which would be slower at low $\mathrm{T}_{\mathrm{a}}$, would be a greater limitation to shoot growth than water availability. Under cooler conditions, the evapotranspiration rates would be lower and the likelihood of development of internal water deficits, which would restrict shoot growth, would be lower. In contrast, under warm dry conditions, water availability would be a greater 
limitation than nitrogen availability and consequently WUE responds more to irrigation than fertilizer application.

The $T_{E}$ values measured in terms of $\mathrm{kg} \mathrm{ha}^{-1}$ (made tea) $\mathrm{mm}^{-1}$ of water transpired can be directly converted to gram of biomass produced per kilogram of water transpired when a harvest index (i.e. ratio of made tea yield to total bush dry weight) of 0.10 (Carr and Stephens, 1992) is assumed. The $\mathrm{T}_{\mathrm{E}}$ and WUE values obtained by both Anandacoomaraswamy et al. (2000) and Stephens and Carr (1991b) are higher than the compiled ranges of $T_{E}$ for $C_{3}$ plant species, i.e. $0.68-1.44 \mathrm{~g} \mathrm{~kg}^{-1}$ (Jones, 1992) and 0.88$2.65 \mathrm{~g} \mathrm{~kg}^{-1}$ (Shantz and Piemeisel, 1927 as compiled by Jones, 1992). Whether this indicates a greater intrinsic capacity of tea to use water more efficiently needs to be ascertained through more accurate estimates of $T_{E}$ and WUE. The inverse relationship between $T_{E}$ and VPD of the growing environment means that their product $\mathrm{T}_{\mathrm{E}} \mathrm{x} V \mathrm{VD}$ is approximately constant (Tanner and Sinclair, 1983; Monteith, 1986). Compiling data from several works, Squire (1990) showed that the product $T_{E} \times$ VPD was around 4.0$5.0 \mathrm{~g} \mathrm{~kg}^{-1} \mathrm{kPa}$ for a range of $\mathrm{C}_{3}$ crops. In comparison, the corresponding value obtained by Anandacoomaraswamy et al. (2000) for tea was $6.9 \mathrm{~g} \mathrm{~kg}^{-1} \mathrm{kPa}$. In addition to the environmental factors described above, Wijeratne et al. (2007a) reported that WUE of tea is influenced by $C_{\mathrm{a}}$ as well. Accordingly, higher $C_{\mathrm{a}}\left(600 \mu \mathrm{mol} \mathrm{mol}^{-1}\right)$ enhanced $\mathrm{P}_{\mathrm{n}}$ and reduced transpiration, and thereby increased WUE of tea at higher $C_{\mathrm{a}}$.

Effects of water deficits on tea yield and yield components: Most of the tea growing in different regions of the world experiences SWD of varying magnitudes and durations. Periods of SWD often coincide with higher VPD and higher $T_{a}$. The effects of water deficits on tea yield can be predicted by examining the effects on the two principal yield components, $\mathrm{N}_{\mathrm{sh}}$ and $\mathrm{W}_{\text {sh }}$. Carr et al. (1987) observed that the rate of shoot production, which primarily determines $\mathrm{N}_{\mathrm{sh}}$, decreased when the average midday shoot $\psi_{\mathrm{w}}$ fell below -0.6 to $-0.7 \mathrm{MPa}$. Squire and Callander (1981) observed this limiting shoot $\psi_{\mathrm{w}}$ to be -0.8 MPa. Shoot $\psi_{\mathrm{w}}$ could fall below the limiting value due to an increase of SWD during prolonged rainless periods. Interestingly, the limiting shoot $\psi_{\mathrm{w}}$ could be reached even when tea is growing on a wet soil, if the VPD increases beyond a threshold (Williams, 1971). Carr et al. (1987) identified this threshold VPD to be around $2 \mathrm{kPa}$.
Wijeratne and Fordham (1996) found that shoot $\psi_{\mathrm{w}}$ of tea decreased linearly with rising SWD above $30-40 \mathrm{~mm}$ at low altitudes in Sri Lanka.

Influence of vapour pressure deficit: Tea is one of the plant species which has been shown to be highly sensitive to atmospheric VPD of the growing environment. During the dry periods of many tea growing regions of the world, VPD could rise to levels which would influence $g_{s}$, shoot $\psi_{\mathrm{w}}$ and the rates of shoot initiation and extension (Squire and Callander, 1981). In addition, VPD influences these key processes of yield formation of tea even during periods when the soil is wet. Furthermore, the linear relationship between shoot extension rate and temperature breaks down at higher VPD (Squire and Callander, 1981). During wet periods with frequent rain, shoot $\psi_{w}$ of tea has an inverse, linear relationship with VPD (Williams, 1971; Squire, 1976, 1979). This probably operates through the influence of VPD on transpiration, which increases with increasing VPD causing a decrease in shoot $\psi_{w}$. During these wet periods, VPD did not exceed $2 \mathrm{kPa}$ and shoot $\psi_{\mathrm{w}}$ did not fall below -1 MPa. Furthermore, during wet periods, this relationship did not show hysteresis. However, it broke down during dry periods, with shoot $\psi_{\mathrm{w}}$ quickly falling to around -1.5 to $-2.0 \mathrm{MPa}$ during the early part of the day around $0900 \mathrm{~h}$ and then remaining at this minimum level while the VPD continued to increase up to $4.0 \mathrm{kPa}$. Moreover, even if the VPD decreased during the latter part of the day, shoot $\psi_{w}$ remained at its minimum until the end of the day. Even when shoot $\psi_{\mathrm{w}}$ began to rise again during late afternoon, it showed hysteresis and lagged behind the decrease of VPD. Irrigated tea bushes during the dry period showed a similar diurnal pattern but their minimum shoot $\psi_{\mathrm{w}}$ was about $0.8 \mathrm{MPa}$ higher. Interestingly, when the soil was re-wetted by rains at the end of the dry season, the linear relationship between short $\psi_{\mathrm{w}}$ and VPD was re-established and shoot $\psi_{\mathrm{w}}$ quickly returned to its higher values (i.e. $>-1 \mathrm{MPa}$ ). This indicated that the roots in the top soil $(0-15 \mathrm{~cm})$ had remained alive during the dry period. Despite the absence of a clear relationship between shoot $\psi_{w}$ and VPD during dry periods on a diurnal basis, Squire (1979) found a close inverse relationship between the weekly rate of shoot extension and mean VPD measured at $1400 \mathrm{~h}$ during the dry season in Malawi. 
Influence of increasing VPD and decreasing shoot $\psi_{w}$ on shoot growth: In addition to decreasing the rate of shoot initiation, decreasing shoot $\psi_{w}$, induced by either increasing VPD or SWD, decreases SER. Shoot extension rates have been found to be inversely related to VPD (Squire, 1979). Tanton (1982a) found that the relative shoot extension rate (RSER) was not affected by VPD when it was below $2.3 \mathrm{kPa}$. However, when VPD rose above $2.3 \mathrm{kPa}$, RSER decreased linearly with increasing VPD so that RSER was reduced by $75 \%$ at $4.0 \mathrm{kPa}$. This reduction of RSER occurs because of the reduction in shoot $\psi_{w}$ caused by increasing VPD. Odhiambo et al. (1993) showed for tea growing at high altitude $(2710 \mathrm{~m}$ a.s.1.) in Kenya that prolonged SWD (>80 mm) and high VPD s $(>2.2 \mathrm{kPa})$ reduced shoot $\psi_{\mathrm{w}}, \mathrm{N}_{\mathrm{sh}}$, SER and leaf yield. Furthermore, a relatively drought susceptible cultivar had a lower shoot $\psi_{w}, \mathrm{SER}, \mathrm{N}_{\mathrm{sh}}$, rate of shoot regeneration and yield than more drought tolerant cultivars during periods of high SWD and high VPD. Smith et al. (1993c) also found a significant decrease in exponential RSER with increasing VPD for tea growing in Malawi.

During periods of rainfall, when VPD is below $2 \mathrm{kPa}, \mathrm{T}_{\mathrm{a}}$ is the main determinant of SER. Tanton (1982b) observed a linear relationship between RSER and $\mathrm{T}_{\mathrm{a}}$ above $\mathrm{a} \mathrm{T}_{\mathrm{b}}$ of $12.5^{\circ} \mathrm{C}$. However, during dry periods, shoot $\psi_{\mathrm{w}}$ becomes the main determinant of shoot growth rate. According to the relationships between VPD and shoot $\psi_{w}$ developed by Williams (1971) and Squire (1976, 1979), the limiting VPD of $2.3 \mathrm{kPa}$ observed by Tanton (1982a) is equivalent to a shoot $\psi_{\mathrm{w}}$ of -0.8 to $-1.0 \mathrm{MPa}$, which is close to the limiting shoot $\psi_{\mathrm{w}}$ for shoot initiation as well. Therefore, both shoot initiation rate and SER of tea are reduced when shoot $\psi_{w}$ decreases below a threshold of around 0.7 to $-1.0 \mathrm{MPa}$. Accordingly, tea yield would also reduce below this threshold as observed, for example by Carr (1971b). Reduction of tea yields during prolonged dry periods have been observed by many workers in several tea-growing regions of the world (Carr, 1974; Carr et al., 1987; Stephens and Carr, 1991a; Othieno et al., 1992; Burgess and Carr, 1993; Nixon et al., 2001; De Costa and Surenthran, 2005).

A characteristic phenomenon of tea is the rapid increases of yield on re-wetting of the soil following a dry period (Fordham and Palmer-Jones, 1977). This is caused by the rapid extension of the large number of shoots that had initiated but had remained dormant on the plucking table because of the lower shoot $\psi_{\mathrm{w}}$ during the dry period. Re-wetting of the soil coupled with the lowering of VPD by rains quickly increases shoot $\psi_{\mathrm{w}}$ above the threshold of $-1 \mathrm{MPa}$ and allows rapid extension of the initiated shoots.

While the leaf appearance rate ( 1 /phyllochron) is primarily related to $T_{a}$, it is also influenced by increasing water deficits, both soil and atmospheric, during a drought. Burgess and Carr (1998) showed that the phyollochron increased from 5.8-7.9 d during the warm, wet season to 11-19 d during the cool, dry season probably because of the influence of lower temperatures and lower shoot $\psi_{w}$. Wijeratne (1994) also showed that the phyllochron of tea seedlings grown in controlled environmental growth chambers increased from $5.70 \mathrm{~d}$ under well-watered conditions to $7.46 \mathrm{~d}$ under water stressed conditions. Similarly, water stress reduced SER (from 10.78 to $6.65 \mathrm{~mm} \mathrm{wk}^{-1}$ ) and leaf expansion rate (from 5.18 to $1.99 \mathrm{~cm}^{2} \mathrm{wk}^{-1}$ ) in the same plants. All these results show that water stress reduces both the rates of leaf production, leaf expansion and shoot extension in tea and thereby reduces the number of shoots that develop up to the pluckable stage within a given time period. Consequently, yield is reduced as a result of reductions in both $\mathrm{N}_{\mathrm{sh}}$ and $\mathrm{W}_{\mathrm{sh}}$.

Critical soil water deficit and response to irrigation: The level of SWD at which plant processes or yield (which is the integration of all processes) begin to be affected significantly is termed the 'critical soil water deficit (CSWD)'. The CSWD for reducing tea yield has been found to vary from 40-200 mm (Stephens and Carr, 1989; Carr and Stephens, 1992; Burgess, 1993). Wijeratne and Fordham (1996) reported that $\mathrm{N}_{\text {sh }}, \mathrm{W}_{\mathrm{sh}}$, shoot extension rate and shoot $\psi_{w}$ of tea were significantly reduced when SWD exceeded 30-40 $\mathrm{mm}$. In contrast, Stephens and Carr (1994) found that the reduction in tea yield due to SWD was more due to restricted shoot extension than due to reduced number of activelygrowing shoots. Hence, they concluded that the critical SWD for shoot extension should also be close to 30-40 $\mathrm{mm}$. Because of the close functional link between shoot $\psi_{\mathrm{w}}$ and SER, the CSWD should be related to a critical 
shoot $\psi_{\mathrm{w}}$. Carr (1971b) showed that the critical shoot $\psi_{\mathrm{w}}$ for reduction and shoot extension and thereby reduction of tea yield was around -0.7 to $-0.8 \mathrm{MPa}$. In a study which showed significant cultivar variation in drought sensitivity, the cultivars with the lowest relative reduction in yield in response to drought had the highest $\psi_{w}$, highest $g_{\mathrm{s}}$ and the highest ratios of $\mathrm{CO}_{2}$ fixed to $\mathrm{H}_{2} \mathrm{O}$ transpired (Smith et al., 1993c).

Furthermore, Wijeratne (1994) found that the plastochron of tea increased with increasing SWD. Wijeratne (2004) also observed that the CSWD for dry matter accumulation in harvested shoots was slightly higher for a relatively drought-tolerant genotype than for a drought-susceptible genotype growing at low altitude (60 m a.s.1.) in Sri Lanka. In contrast, Othieno et al. (1992) observed the CSWD to be $85-100 \mathrm{~mm}$ for tea growing at high altitude $(2178 \mathrm{~m}$ a.s.1., which is close to the upper limit for economically-viable production of tea) in Kenya. The lower VPD, which rarely exceeds the critical value of $2.3 \mathrm{kPa}$ at high altitude (Tanton, 1982a) was mainly responsible for the higher CSWD in this environment.

The feasibility of irrigation has been explored as a means of countering the adverse effects of SWD. Stephens and Carr (1991a) showed that in a situation where VPD is not high enough to restrict shoot extension, yield of well-fertilized tea increased by $2.9 \mathrm{~kg} \mathrm{ha}^{-1}$ for each $\mathrm{mm}$ of SWD reduced through irrigation. Unfertilized tea showed a lower response to irrigation with $1.4 \mathrm{~kg} \mathrm{ha}^{-1} \mathrm{~mm}^{-1}$. This experiment was done in an area with a dry period of up to six months per year during which the SWD increases up to 600-700 $\mathrm{mm}$. Therefore, Stephens and Carr (1991a) showed that the yield gain through irrigation substantially outweighed the additional cost involved. Field observations in Sri Lanka have shown that drip irrigation increased tea yield by $50-100 \%$. Furthermore, yield response to irrigation could be as high as 300\% during dry weather (Anonymous 2001, 2002). In contrast, the yield loss due to increasing SWD is lower at higher altitudes where VPD is also low. For example, Othieno et al. (1992) observed a yield loss of $1.3 \mathrm{~kg} \mathrm{ha}^{-1} \mathrm{~mm}^{-1}$ of SWD at high altitude in Kenya during the dry season where the potential SWD could increase up to $400 \mathrm{~mm}$.

In a detailed study, Nixon et al. (2001) showed a clear difference between young (i.e. five-year-old) and mature tea (22-year-old) in their susceptibility to drought and response to irrigation. As expected, young tea was more susceptible to drought than mature tea. The critical SWD required for causing a significant yield reduction on an annual basis was 200-250 mm for young tea as compared to $400-500 \mathrm{~mm}$ for mature tea. Furthermore, the rate of reduction of annual yield with increasing SWD was $22 \mathrm{~kg}$ $\mathrm{ha}^{-1} \mathrm{~mm}^{-1}$ (SWD) in young tea as against $6.5 \mathrm{~kg} \mathrm{ha}^{-1} \mathrm{~mm}^{-1}$ in mature tea. The lower sensitivity of annual yields of mature tea was primarily because it was able to compensate for part of the yield loss that occurred during the dry period by having a substantially higher yield during the wet period of the year. Nixon et al. (2001) related the differential responses of young and mature tea to variation in their root systems and shoot-root dry matter partitioning. Interestingly, mature tea had four times more structural roots $(>1 \mathrm{~mm}$ diameter) and eight times more fine roots ( $<1 \mathrm{~mm}$ diameter) than young tea. More importantly, the weight of fine root per unit of canopy area in mature tea was six times greater than in young tea, which enabled mature tea a greater capacity to extract and supply water to the foliage canopy during a dry period.

Burgess and Carr (1993, 1996b) showed significant variation in drought sensitivity (measured as the reduction in yield per unit increase in time-integrated SWD above a CSWD) among different genotypes of tea growing in Tanzania. The genotype which showed the highest drought sensitivity had the highest yield under irrigation, but showed the greatest yield reduction with increasing SWD. The drought resistant genotypes were able to maintain a greater crop canopy cover than the susceptible genotypes during the dry period. Burgess and Carr (1996b) also showed that the CSWD for yield reduction on annual basis $(70-90 \mathrm{~mm})$ was greater than that for yield reduction during the dry season (40-50 $\mathrm{mm}$ ). This is because of the contribution to wet season yield from shoots, which are initiated during the drought period. These grow up to the harvestable stage only after the relief of drought during the wet season.

\section{PARTITIONING OF BIOMASS, HARVEST INDEX AND YIELD}

Biomass partitioning: Photoassimilates originating in the foliage canopy of tea have to be partitioned to new shoots for yield formation and to other parts of the bush 
(i.e. maintenance foliage, branches, stem and root system) for further growth of the bush. Particularly, the fraction of assimilates partitioned to new shoots determines $\mathrm{W}_{\mathrm{sh}}$ and thereby partly determines tea yield. Wijeratne (2004) estimated the annual dry matter accumulation in young tea shoots to be around 10-13 $\mathrm{tha}^{-1}$ $\mathrm{yr}^{-1}$. Out of this $48-58 \%$ was harvested and the rest was added to the canopy.

Growing shoots of tea act as a strong sink for photosynthates (Rahman, 1988). The respective relative sink capacities of a bud, one bud and a young leaf, and two leaves and a bud were $100 \%, 75 \%$ and $35 \%$, respectively. The mature leaves (i.e. maintenance leaves) produce photosynthates to meet the demand of the growing shoots and other organs. The direction of movement of photosynthesis depends on the presence or absence of shoots on the plucking table. The presence of young, growing shoots results in upward movement of a relatively greater proportion of photosynthates.

In intact bushes, the carbon assimilated by mature leaves readily move into the developing shoot tips, and become generally distributed in the shoots in $c a .24 \mathrm{~h}$ (Sanderson and Sivapalan, 1966b). Movement of photosynthates into dormant buds is much less than into actively-growing buds. Photosynthates produced in immature tea leaves do not move out of the same leaves nor move out into other mature leaves. Older leaves do not become parasitic on other leaves when they become unproductive. The assimilated carbon tends to divide itself between upward movement towards the shoot tips and downwards towards the stems and roots. In a study carried out by using ${ }^{14} \mathrm{C}$ in unpruned tea, at monthly intervals in a year, only $11 \%$ of photosynthates produced by the maintenance leaves were allocated to the commercially useful shoots (Barman and Saikia, 2005). The photosynthetically active maintenance leaves retained $19 \%$ and $25 \%$ was distributed to the branches. The roots utilized $31 \%$ of net photosynthates.

At the crop level, biomass partitioning of tea has been observed to vary with genotype (Burgess and Carr, 1996a, b; Navaratne et al., unpublished results), season (Burgess and Carr, 1996a), water availability (Burgess and Carr, 1996a), stage of the pruning cycle (Navaratne et al., unpublished results) and mineral nutrition (Anandacoomaraswamy et al.,
2002). Less biomass is partitioned to harvested shoots at cooler temperatures, at higher SWDs, during the latter part of the pruning cycle and under lower nitrogen supply. Conversely, greater biomass is partitioned to roots at cooler temperatures and under lower $\mathrm{N}$ supply. However, contrary to expectations, there was no observable shift in biomass partitioning towards roots during dry periods (Burgess and Carr, 1996a). Nevertheless, root growth of tea was much less sensitive than shoot and leaf growth to low soil $\psi_{\mathrm{w}}$ (Burgess and Carr, 1996a).

Harvest index: Harvest index (HI) plays a critically important role in yield determination of tea. For example, a greater partitioning of biomass to harvested leaves was identified as the principal reason for the superior yield potential of the higher yielding genotypes examined by Burgess and Carr (1996a). Navaratne et al. (unpublished results) also identified decreasing $\mathrm{HI}$ as the major factor causing the yield decline of tea during the latter part of its pruning cycle.

The low percentage of photosynthates partitioned to harvestable shoots is commensurate with the very low $\mathrm{HI}$ values obtained for tea (Hadfield, 1974; Tanton, 1979; Magambo and Cannell, 1981). The reported values of HI of tea range from 0.10 to 0.20 , compared to $0.30-0.70$ in tropical grasslands, forests and root crops (Tanton, 1979; Magambo and Cannel, 1981; Barbora and Barua, 1988). For a high yielding (i.e. $5600 \mathrm{~kg} \mathrm{ha}^{-1} \mathrm{yr}^{-1}$ ) genotype under irrigation, Burgess and Carr (1996a) reported a HI of 0.24, which was substantially greater than the other reported values for tea. Wijeratne (2001) reported that harvesting policies, particularly the severity of harvesting, have a significant influence on HI. Experimental observations have shown that fish leaf plucking (removing a shoot immediately above the fish leaf; Figure 4) harvests about $80 \%$ of the total biomass of a shoot while single leaf plucking (removing a shoot immediately above the most matured true leaf) harvests only around $40 \%$ of the total biomass of the shoot. Tanton (1979) and Wijeratne (2001) have shown that plucking of young shoots, which are strong sinks for partitioning of assimilates, is the main reason for the lower $\mathrm{HI}$ of tea.

Yield: The harvested leaf yield of tea (i.e. made tea) can generally reach 4-5 t ha- $\mathrm{yr}^{-1}$ under favourable climatic and soil conditions with proper management. There are 
occasions where yields up to $6.5 \mathrm{t} \mathrm{ha}^{-1} \mathrm{yr}^{-1}$ have been reported (Carr and Stephens, 1992). Even at these upper limits, tea yields are much lower than the 10-20 $\mathrm{tha}^{-1} \mathrm{yr}^{-1}$ range of yields for crops in which a vegetative part is harvested. Reasons for this lower yield potential of tea were discussed earlier in this section. In the absence of soil constraints, tea yields under proper management are higher at lower elevations than at higher elevations. Both climatic and soil constraints would reduce tea yields from their upper limits under optimum conditions. Out of the two yield components of tea (i.e. $\mathrm{N}_{\mathrm{sh}}$ and $\mathrm{W}_{\mathrm{sh}}$ ), it is the variation of $\mathrm{N}_{\mathrm{sh}}$ that has the stronger correlation with yield variation.

\section{RESPONSE OF TEA TO CLIMATE CHANGE}

Long-term gradual climate change involves increasing $C_{\mathrm{a}}$ and the consequent warming of the atmosphere. The rising $\mathrm{T}_{\mathrm{a}}$ triggers a variety of changes in the atmosphere leading to modified rainfall patterns, evapotranspiration rates and VPD. Because of the close relationships between tea yield and these atmospheric variables, long-term climate change is likely to cause significant impacts on the key physiological and developmental processes that determine the yield and yield components of tea (Wijeratne, 1996). Responses to different aspects of climate change can be both positive and negative. A clear positive effect is the response to increased $C_{\mathrm{a}}$ through increased photosynthetic rates (Anandacoomaraswamy et al., 1996) and yields. However, there can be substantial genotypic variation in the response to increased $C_{\mathrm{a}}$. For example, Anandacoomaraswamy et al. (unpublished results) showed that while the total dry weights and root dry weights of sand-cultured, nine-month-old tea seedlings of one genotype (TRI 3019) increased significantly at elevated $C_{\mathrm{a}}$ over a three-month period of $\mathrm{CO}_{2}$ enrichment at high altitude, those of another genotype (TRI 3072) did not show a significant response under the same conditions. Such genotypic variation in the response to elevated $C_{\mathrm{a}}$ has been shown for other crops (De Costa et al., 2007 for rice) and natural plant species (Poorter and Navas, 2003) as well.

In two $\mathrm{CO}_{2}$ fertilization field experiments carried out over a period of 18 months at low (60 m a.s.1.) and high (1380 m a.s.1.) elevations in Sri Lanka, Wijeratne et al. (2007b) showed that an increase of $C_{\mathrm{a}}$ from the present ambient level of $370 \mu \mathrm{mol} \mathrm{mol}^{-1}$ to $600 \mu \mathrm{mol} \mathrm{mol}{ }^{-1}$ (which is predicted to occur during the middle of this century) increased tea yields in Sri Lanka by 33 and 37\% at high and low elevations, respectively. The long-term averages of maximum/minimum temperatures at the high and low elevations were $20.5 \%$ $11.5^{\circ} \mathrm{C}$ and $32.0^{\circ} / 22.9^{\circ} \mathrm{C}$, respectively. Increases in both $\mathrm{N}_{\mathrm{sh}}$ and $\mathrm{W}_{\mathrm{sh}}$ contributed to these yield increases. Tea at elevated $C_{\mathrm{a}}$ also showed higher $\mathrm{P}_{\mathrm{n}}$ and transpiration rates than at ambient $C_{\mathrm{a}}$ (Wijeratne et al., 2007a).

The study of Wijeratne et al. (2007b) also identified several climate change-induced variables which would have negative impacts on tea yields and thereby reduce the potential yield gains due to increasing $C_{\mathrm{a}}$. Particularly, a quadratic relationship, with the optimum around $22^{\circ} \mathrm{C}$, was found between monthly tea yield and monthly mean $\mathrm{T}_{\mathrm{a}}$ during 'wet' periods. Similarly, a quadratic relationship was found between monthly tea yield and rainfall of the previous month. These data were used in a simulation model to predict the impacts of increasing $C_{\mathrm{a}}$, increasing $\mathrm{T}_{\mathrm{a}}$ and varying rainfall on tea yields at different altitudes. Results of the simulations showed that the yield increases due to increasing $C_{\mathrm{a}}$ were augmented by increasing $\mathrm{T}_{\mathrm{a}}$ at high altitudes (Table 4). However, at low altitudes, yield gains of higher $C_{\mathrm{a}}$ were pulled back because the rising $\mathrm{T}_{\mathrm{a}}$ pushed the already high $\mathrm{T}_{\mathrm{a}}$ in to the supra-optimal range for most of the key physiological processes that determine yield. Predicted tea yields by the year 2050 under the climate change scenarios specified by different Global Circulation Models also showed increased yields at higher altitudes, but reduced yields at lower altitudes (Table 4).

Acknowledgements: The authors gratefully acknowledge the assistance of Prof. M.K.V. Carr, who provided reprints of publications containing a substantial amount ecophysiological work carried out by him and his co-workers on tea. Almost all the work of the authors of this paper that has been cited here has been funded and supported by the Tea Research Institute of Sri Lanka, its staff and numerous undergraduate and postgraduate students. We are much grateful to all of them. We owe a special word of thanks to our friend and colleague, up to the time of his recent retirement, Dr. A. Anandacoomaraswamy, who has been a substantial contributor to many of the Sri Lankan work cited herein. 
Table 4. Projected tea yields at four locations in Sri Lanka under different scenarios of climate change (increase in temperature by 1 and $2^{\circ} \mathrm{C}$, increase in rainfall by $10 \%$, decrease in rainfall by $10 \%$ and increase in ambient $\mathrm{CO}_{2}$ concentration up to $435 \mu \mathrm{mol} \mathrm{mol}^{-1)}$ for the year 2050. Location characteristics: altitude (m a.s.l.), maximum/minimum temperature, and annual rainfall: Ratnapura $=60 \mathrm{~m}, 32.0 / 22.9^{\circ} \mathrm{C}, 3617 \mathrm{~mm}$; Kandy $=472 \mathrm{~m}, 29.0 / 20.2^{\circ} \mathrm{C}, 1863 \mathrm{~mm}$; Nuwara Eliya $=2013 \mathrm{~m}$, 20.5/11.5 ${ }^{\circ}$, $907 \mathrm{~mm}$; Passara $=1028 \mathrm{~m}, 28.7 / 18.5^{\circ} \mathrm{C}, 1777 \mathrm{~mm}$. Source: (Wijeratne et al., 2007b).

\begin{tabular}{|c|c|c|c|c|c|c|}
\hline \multirow{2}{*}{$\begin{array}{l}\mathrm{CO}_{2} \\
(\mu \mathrm{mol} \\
\left.\mathrm{mol}^{-1}\right)\end{array}$} & \multirow{2}{*}{$\begin{array}{c}\text { Rainfall } \\
\text { change }(\%)\end{array}$} & \multirow{2}{*}{$\begin{array}{l}\text { Temperature } \\
\text { change }\left({ }^{\circ} \mathrm{C}\right)\end{array}$} & \multicolumn{4}{|c|}{ Yield $\left(\mathrm{kg} \mathrm{ha}^{-1} \mathrm{yr}^{-1}\right)$} \\
\hline & & & Ratnapura & Kandy & N'Eliya & Passara \\
\hline 370 & 0 & 0 & 2489 & 2217 & 2454 & 2651 \\
\hline 370 & 0 & 1 & 2282 & 2177 & 2651 & 2569 \\
\hline 370 & 0 & 2 & 2070 & 2117 & 2760 & 2469 \\
\hline 370 & -10 & 0 & 2456 & 2161 & 2418 & 2591 \\
\hline 370 & 10 & 0 & 2482 & 2305 & 2480 & 2749 \\
\hline 435 & 0 & 0 & 2710 & 2695 & 3035 & 3080 \\
\hline 435 & 0 & 1 & 2502 & 2567 & 3035 & 2998 \\
\hline
\end{tabular}

\section{REFERENCES}

Ahmed N, Chakrabooty, H, Hasan KA (1965) Effect of Gibberellic acid on the growth of tea seedlings. Tea J. Pakistan 3:46-48.

Anandacoomaraswamy A, De Costa WAJM, Gawarammana MDW, Navaratna DMS (1996) Effect of soil moisture stress on physiological parameters of young tea. In: Proceedings of the $193^{\text {rd }}$ Experiments and Extension Forum of the Tea Research Institute of Sri Lanka. Talawakelle, Sri Lanka, pp. 17-35.

Anandacoomaraswamy A, De Costa WAJM, Shyamalie HW and Campbell GS (2000) Factors controlling transpiration of mature field-grown tea and its relationship with yield. Agric. For. Meteorol. 103:375-386.

Anandacoomaraswamy A, De Costa WAJM, Tennakoon PLK, Van der Werf A (2002) The physiological basis of increased biomass partitioning to roots upon nitrogen deprivation in young clonal tea (Camellia sinensis (L.) O. Kuntz). Plant Soil 238:1-9.

Anonymous (2001, 2002) Reports of the Agronomy Division, Annual Reports, 2001 \& 2002. The Tea Research Institute of Sri Lanka, Talawakelle, Sri Lanka. Aoki S (1987) Varietal differences and effects of nitrogen fertilization on decline of photosynthetic rate in overwintering tea leaves. Jap. J. Crop Sci. 56:252-256.

Arunachalam K (1995) Handbook on Indian Tea. Arunachalam Associates, Nilgris.

Balasimha D, Daniel EV, Bhat PG (1991) Influence of environmental factors on photosynthesis in cocoa trees. Agric. For. Meteorol. 55:23-36.
Balasooriya J (1996) Effect of altitude on shoot development of clonal tea with special reference to clonal selection and harvesting intervals. Sri Lank. J. Tea Sci. 64:51-62.

Barbora AC, Barua DN (1988) Respiratory loss and partition of assimilates in tea bushes (Camellia sinensis L.) under plucking. Two Bud 35:75-82.

Barman TS, Saikia JK (2005) Retention and allocation of ${ }^{14} \mathrm{C}$ assimilates by maintenance leaves and harvest index of tea (Camellia sinensis L.). Photosynthetica 43:283-287.

Barua DN (1960) Effect of age and carbon dioxide concentration on assimilation by detached leaves of tea and sunflower. J. Agric. Sci. 55:413-415.

Barua DN (1969) Seasonal dormancy in tea (Camellia sinensis L.). Nature 224:514.

Barua DN, Das SC (1979) Mechanisms of growth periodicity of tea. Two Bud 26:36-40.

Bierhuizen JF, Slatyer RO (1965) Effect of atmospheric concentration of water vapour and $\mathrm{CO}_{2}$ in determining transpiration-photosynthesis relationships. Agric. Meteorol. 2:259-270.

Bond TET (1942) Studies in the vegetative growth and anatomy of the tea plant (Camellia thea Link.) with special reference to the phloem: I. Flush shoots. Ann. Bot. 6:607-629.

Bond TET (1945) Studies in the vegetative growth and anatomy of the tea plant (Camellia thea Link.) with special reference to the phloem: II. Further analysis of flushing behaviour. Ann. Bot. 9:183-216. 
Boote KJ, Loomis RS (1991) The prediction of canopy assimilation. In: Boote KJ, Loomis RS (eds), Modelling Crop Photosynthesis - from Biochemistry to Canopy, pp. 109-140. American Society of Agronomy and Crop Science Society of America, Madison, Wisconsin, USA.

Burgess PJ (1993) An update on the yield responses of young tea clones to drought. Ngwazi Tea Research Unit, Quarterly Report, No. 12:8-17.

Burgess PJ, Carr MKV (1993) Response of tea (Camellia sinensis) clones to drought. I. Yield, dry matter production and partitioning. Aspects Appl. Biol. 34:249-258.

Burgess PJ, Sanga BNK (1994) Dry weight and root distribution of mature tea. Ngwazi Tea Research Unit Quarterly Report 17:11-21.

Burgess PJ, Carr MKV (1996a) Responses of young tea (Camellia sinensis) clones to drought and temperature. II. Dry matter production and partitioning. Exp. Agric. 32:377-394.

Burgess PJ, Carr MKV (1996b) Responses of young tea (Camellia sinensis) clones to drought and temperature. I. Yield and yield distribution. Exp. Agric. 32:357-372.

Burgess PJ, Carr MKV (1998) The use of leaf appearance rates estimated from measurements of air temperature to determine harvest intervals for tea. Exp. Agric. 34:207-218.

Callander BA (1978) Eddy correlation measurements of sensible heat flux density. Glasgow, University of Strathclyde, $\mathrm{PhD}$ thesis.

Callander BA, Woodhead T (1981) Canopy conductance of estate tea in Kenya. Agric. Meteorol. 23:151-167.

Carr MKV (1970) The role of water in the growth of the tea crop. In: Lukwill LC, Cutting CV (eds) Physiology of Tree Crops, pp.287-384. Academic Press, London.

Carr MKV (1971a) An assessment of some of the results of tea/soil/water studies in Southern Tanzania. In: Carr MKV, Carr S (eds), Water and the Tea Plant, pp.21-47. Tea Research Institute of East Africa, Kericho, Kenya. Carr MKV (1971b) The internal water status of the tea plant (Camellia sinensis): some results illustrating the use of the pressure chamber technique. Agric. Meteorol. 9:447-460.

Carr MKV (1972) The climatic requirements of the tea plant: A review. Exp. Agric. 8:1-14.
Carr MKV (1974) Irrigating seedling tea in Southern Tanzania: effects on total yields, distribution of yield and water use. J. Agric. Sci. (Cambridge) 83:363-378.

Carr MKV (1977a) Changes in the water status of tea clones during dry weather in Kenya. J. Agric. Sci. (Cambridge) 89:297-307.

Carr MKV (1977b) Responses of seedling tea bushes and their clones to water stress. Exp. Agric. 13:317-324.

Carr MKV (1985) Some effects of shelter on the yield and water use of tea. In: Grace J (ed), Effects of Shelter on the Physiology of Plants and Animals, Progress in Biometeorology, Vol. 2, pp.127-144. Swets \& Zeitlinger B. V., Lisse.

Carr MKV (2000) Shoot growth plus plucking equals profit. TRIT Occasional Publication No. 1, April 2000, Tea Research Institute of Tanzania, pp.1-7.

Carr MKV, Stephens W (1992) Climate, weather and the yield of tea. In: Willson KC, Clifford MN (eds), Tea: Cultivation to Consumption, pp.87-135. Chapman \& Hall, London.

Carr MKV, Dale MO, Stephens W (1987) Yield distribution in irrigated tea (Camellia sinensis) at two sites in Eastern Africa. Exp. Agric. 23:75-85.

Charles-Edwards DA (1982) Physiological Determinants of Crop Growth. Academic Press, London.

Cooper JD (1979) Water use of a tea estate from soil moisture measurements. East Afr. Agric. For. J. 43:102121.

Corley RHV, Gray BS, Ng SK (1971) Productivity of the oil palm (Elaeis guineensis Jacq.) in Malaysia. Exp. Agric. 7:129-136.

Dagg M. (1970) A study of the water use of tea in East Africa using a hydraulic lysimeter. Agric. Meteorol. 7:303-320.

Davies WJ, Zhang J (1991) Root signals and the regulation of growth and development of plants in drying soil. Annu. Rev. Plant Physiol. Plant Mol. Biol. 42:55-76.

De Costa WAJM, Anandacoomaraswamy A, Tennakoon, PLK (2000) Effect of nitrogen supply on the response of leaf photosynthesis to light in young clonal tea. Indian J. Plant Physiol. 5:244-247.

De Costa WAJM, Surenthran P (2005) Tree-crop interactions in hedgerow intercropping with different tree species and tea in Sri Lanka: 1. Production and resource competition. Agrofor. Syst. 63:199-209. 
De Costa WAJM, Weerakoon WMW, Chinthaka KGR, Herath HMLK, Abeywardena RMI (2007) Genotypic variation in the response of rice (Oryza sativa $\mathrm{L}$.) to increased atmospheric carbon dioxide and its physiological basis. J. Agron. Crop Sci. 193:117-130.

Fordham R (1969) The physiological responses of tea to moisture stress and irrigation. Quarterly Newsletter, Tea Research Foundation, Central Africa, No. 13:13-15.

Fordham R (1970) Factors affecting tea yields in Malawi. In: Annual Report, Tea Research Foundation of Central Africa, Mulanje, Malawi, pp. 71-130.

Fordham R (1972) Observations on the growth of roots and shoots of tea (Camellia sinensis) in southern Malawi. J. Hort. Sci. 47:221-229.

Fordham R (1977) Tea. In: Alvim P de T, Kozlowski TT (eds), Ecophysiology of Tropical Crops, pp.333-349. Academic Press, New York.

Fordham R, Palmer-Jones RW (1977) Simulation of intraseasonal yield fluctuations of tea in Malawi. Exp. Agric. 13:33-42.

Gamage AJ, Wijeratne MA, De Costa WAJM (2007) Role of shade trees in tea: A low-country perspective. In: Proceedings of the $215^{\text {th }}$ Meeting of the Experiments and Extension Forum. Tea Research Institute of Sri Lanka, Talawakelle, Sri Lanka.

Gee GW, Sandanam S, Kulasegaram S, Anandacoomaraswamy A (1982) Effect of shade on leaf water diffusion resistance in clonal tea (Camellia sinensis). Tea Quart. 51:12-20.

Goodchild NA (1968) Growth of tea shoot following pruning. Ann. Bot. 32:567-572.

Green MJ (1971) An evaluation of some criteria used in selecting large-yielding tea clones. J. Agric. Sci. (Cambridge) 76:143-156.

Gunasekara HKLK, De Costa WAJM, Nugawela EA (2007) Genotypic variation in canopy photosynthesis, leaf gas exchange characteristics and their response to tapping in rubber (Hevea brasiliensis Muell. Arg.). Exp. Agric. 43:223-239.

Gunawardena VL, Mohotti AJ, Bandara DC, Navaratne DMS (2001) Photosynthesis and some related processes of young tea (Camellia sinensis L.) as affected by short-term water deficit. In: Proceedings of the $57^{\text {th }}$ Annual Sessions of the Sri Lanka Association for Advancement of Science, Part I., pp. 32.
Hadfield W (1974) Shade in North-east India tea plantations II. Foliar illumination and canopy characteristics. J. Appl. Ecol. 11:179-199.

Hadfield W (1975) The effect of high temperatures on some aspects of the physiology and cultivation of the tea bush, Camellia sinensis, in North India. In: Evans GC, Bainbridge R, Rackham O (eds), Light as an Ecological Factor, II, The $16^{\text {th }}$ Symposium of the British Ecological Society, pp.477-495. Blackwell Scientific Publications, Oxford.

Harler CR (1964) The Culture and Marketing of Tea. Oxford University Press, London.

Herd EM, Squire GR (1976) Observations on the winter dormancy in tea. J. Hort. Sci. 51:267-279.

Hoshina T, Kosuge N, Kozai S, Honjo U (1983) Influence of air temperature on nitrogen uptake by the tea plant. Study Tea 64:24-28.

Jinke L, Zhanzijin J, Mingzhi L (1999) Photosynthetic characteristic of Tieguanying tea plant. J. Tea Sci. 19:35-40.

Jones HG (1992) Plants and Microclimate: A Quantitative Approach to Environmental Plant Physiology, 2nd. Edition. Cambridge University Press, Cambridge.

Joshi SC, Palni LMS (1998) Clonal variation in temperature response of photosynthesis in tea. Plant Sci. 137:225-232.

Karunaratne PMAS, Wijeratne MA, Sangakkara UR (1999) Osmotic adjustments and associated water relations of clonal tea. J. Agric. Sci. (Sabaragamuwa) 2:77-85.

Karunaratne PMAS, Mohotti AJ, Nissanka SP, Gunasinghe WADSK (2003) Effect of shade in minimizing photoinhibition of photosynthesis of high grown tea (Camellia sinensis (L.) O. Kuntze). Trop. Agric. Res. 15:133-143.

Kigalu JM (2007) Effects of planting density on the productivity and water use of tea (Camellia sinensis L.) clones I. Measurement of water use in young tea using sap flow meters with a stem heat balance method. Agric. Water Manage. 90:224-232.

Kingdon-Ward F (1950) Does wild tea exist? Nature 165:297-299.

Krishnapillai S, Ediriweera VL (1986) Influence of levels of nitrogen and potassium fertilizers on chlorophyll content in mature clonal tea leaves. Sri Lank. J. Tea Sci. 55:71-76. 
Kulasegaram S (1967) Studies on the dormancy of tea shoots: Hormonal stimulation of the growth of dormant buds. Tea Quart. 40:31-42.

Kulasegaram S, Kathiravetpillai A (1983) Effect of shade, water supply and nitrogen on the distribution of mineral nutrients and total carbohydrate resources in young tea (Camellia sinensis (L.) O. Kuntze). Tea Quart. 52:21-30.

Lakmini WGD, Nainanayake, NPAD, De Costa WAJM (2006) Physiological responses of four coconut (Cocos nucifera L.) genotypes under water stress. In: Proceedings of the International Symposium. Sabaragamuwa University of Sri Lanka, Sri Lanka, pp.26.

Liyanapatabendi NKLP, Mohotti AJ, Sangakkara UR (2007) Rooting behaviour of field grown seedling and vegetatively propagated tea (Camellia sinensis (L.) O. Kuntze). In: Proceedings of the $27^{\text {th }}$ Annual Sessions of the Institute of Biology of Sri Lanka, Sri Lanka, pp.33.

Magambo MJS, Cannell MGR (1981) Dry matter production and partition in relation to yield of tea. Exp. Agric. 17:33-38.

Magambo MJS, Othieno CO (1983) Influence of soil temperature variation on early flowering of tea plants. Tea 4:21-27.

Manivel L (1980) Role of maintenance foliage. Two Bud 27:52-55.

Manivel L, Hussain S (1982) Photosynthesis in tea: Direction of movements of photosynthates. Two Bud 29:49-52.

Matthews RB, Stephens W (1998a) CUPPA-TEA: A simulation model describing seasonal yield variation and potential production of tea. 2. Biomass production and water use. Exp. Agric. 34:369-389.

Matthews RB, Stephens W (1998b) CUPPA-TEA: A simulation model describing seasonal yield variation and potential production of tea. 1. Shoot development and extension. Exp. Agric. 34:369-389.

Mohotti AJ (1998) Effect of irradiance and N nutrition on photosynthesis of tea (Camellia sinensis (L.) O. Kuntze) in comparison with sunflower (Helianthus annus L.). Reading, University of Reading. PhD thesis.

Mohotti AJ (2004) Shade in tea: Is it beneficial? Sri Lank. J. Tea Sci. 69:27-39.

Mohotti AJ, Dennett MD, Lawlor DW (2000) Electron transport as a limitation to photosynthesis of tea
(Camellia sinensis (L.) O. Kuntze): a comparison with sunflower (Helianthus annus L.) with special reference to irradiance. Trop. Agric. Res. 12:1-10.

Mohotti AJ, Lawlor DW (2002) Diurnal variation of photosynthesis and photoinhibition in tea: effects of irradiance and nitrogen supply during growth in the field. J. Exp. Bot. 53:313-322.

Mohotti AJ, Vajirakanthi WMM, Mohotti KM, Bandara DC (2003b) Growth and distribution of tea root system under organic and conventional management systems. In: Programme and Abstracts of Third International Symposium on Dynamics of Physiological Processes in Woody Roots. Perth, Australia. pp.151.

Mohotti AJ, Damayanthi N, Tennakoon KT, Mohotti KM, Sangakkara UR (2003c) Anatomical differences of tea roots grown under organic and conventional management systems. In: Programme and Abstracts of Third International Symposium on Dynamics of Physiological Processes in Woody Roots. Perth, Australia. pp.77.

Mohotti AJ, Wickremaratne DSD, Nissanka SP, Munasinghe PS, Hettiarachchi LSK (2003a) Effect of foliar application of potassium on drought tolerance of young tea (Camellia sinensis L.). In: Proceedings of the $23^{\text {rd }}$ Annual Sessions of Institute of Biology of Sri Lanka. Sri Lanka, pp.8-9.

Monteith JL (1977) Climate and efficiency of crop production in Britain. Phil. Trans. Royal Soc. Lond. B281:277-294.

Monteith JL (1986) How do crops manipulate water supply and demand? Phil. Trans. Royal Soc. Lond. A316:245-259.

Nainanayake AD (2004) Impact of drought on coconut (Cocos nucifera L.): Screening germplasm for photosynthetic tolerance in the field. Colchester, University of Essex. PhD thesis.

Nathaniel RK (1976) Some observations on the growth of clonal tea under low country conditions in Sri Lanka. In: Proceedings of the $22^{\text {nd }}$ Scientific Conference Bulletin, United Planters Association of South India 33:173-183.

Nixon DJ, Sanga BNK (1995) Dry weight and root distribution of unirrigated mature tea. Ngwazi Tea Research Unit Quarterly Report 21:18-23.

Nixon DJ, Burgess PJ, Sanga BNK, Carr MKV (2001) A comparison of the responses of mature and young 
clonal tea to drought. Exp. Agric. 37:391-402.

Nyirenda HE (1989) Effectiveness of assessment of vigour and productivity in young vs old bushes and mature clones (Camellia sinensis). Ann. Appl. Biol. 115:327-332.

Nyirenda HE (1991) Use of growth measurements and foliar nutrient contents as criteria for clonal selection in tea. Exp. Agric. 27:47-52.

Obaga SMO, Squire GR, Langat JK (1988) Altitude, temperature and the growth rate of tea shoots. Tea 9:30-35.

Odhiambo HO, Nyabundi JO, Chweya J (1993) Effect of soil moisture and vapour pressure deficits on shoot growth and the yield of tea in the Kenya Highlands. Exp. Agric. 29:341-350.

Okano K, Komaki S, Matsuo K, Hirose D, Tatsumi J. (1995) Analysis of canopy photosynthesis in mature tea (Camellia sinensis L.) bush at late autumn. Jap. J. Crop Sci. 64:310-316.

Okano K, Matsuo K, Hirose D, Tatsumi J (1996) Photosynthesis and productive structure of mature tea (Camellia sinensis L.) bush during growth of first flush. Jap. J. Crop Sci. 65:108-113.

Othieno CO (1982) Diurnal variations in soil temperature under tea plants. Exp. Agric. 18:195-202.

Othieno CO, Ahn PM (1980) Effects of mulches on soil temperature and growth of tea in Kenya. Exp. Agric. 16:287-294.

Othieno CO, Stephens W, Carr MKV (1992) Yield variability at the Tea Research Foundation of Kenya. Agric. For. Meteorol. 61:237-252.

Pethiyagoda U (1964) Some observations on the dormancy of the tea bush. Tea Quart. 35:74-83.

Poorter H, Navas M-L (2003) Plant growth and competition at elevated $\mathrm{CO}_{2}$ : on winners, losers and functional groups. New Phytol. 157:175-198.

Rahman F (1988) Physiology of the tea bush. Two Bud 35:1-14.

Rahman F, Dutta AK (1988) Root growth in tea. J. Plant. Crops 16:31-37.

Raj Kumar R, Manivel L, Marimuthu S (1998) Longevity and factors influencing photosynthesis in tea leaves. Photosynthetica 35:41-46.

Ranganathan V, Raman K, Natesan S (1983) Nutritional and physiological interactions with length of plucking rounds and banjhiness. Bulletin, United Planters
Association of South India 38:67-89.

Roberts EH, Summerfield RJ, Ellis RH, Craufurd PQ, Wheeler TR (1997) The induction of flowering. In: Wien HC (ed), The Physiology of Vegetable Crops, pp.69-100. CAB International, Wallingford.

Roberts GR, Keys AJ (1978) The mechanism of photosynthesis in the tea plant (Camellia sinensis L.). J. Exp. Bot. 29:1403-1407.

Sakai S (1975) Recent studies and problems of photosynthesis of the tea plant. JARQ 9:101-106.

Sakai S (1987) Studies on photosynthesis and dry matter production of tea plants. Bulletin of the National Research Institute of Tea. National Research Institute of Tea, Kanaga, Shizuoka, Japan.

Sandanam S, Gee GW, Mapa RB (1981) Leaf water diffusion resistance in clonal tea (Camellia sinensis L.): Effects of water stress, leaf age and clones. Ann. Bot. 47:339-349.

Sanderson GW, Sivapalan K (1966a) Effect of leaf age on photosynthetic assimilation of carbon dioxide in tea plants. Tea Quart. 37:11-26.

Sanderson GW, Sivapalan K (1966b) Translocation of photosynthetically assimilated carbon in tea plants. Tea Quart. 37:140-153.

Shanmugarajah V, Kulasegaram S, Senanayake YDA (1991) Nursery plant attributes as criteria for selection of new clones. Sri Lank. J. Tea Sci. 60:76-86.

Shantz HL, Piemeisel LN (1927) The water requirements of plants at Akron, Colorado. J. Agric. Res. 34:10931190.

Sivapalan K (1975) Photosynthetic assimilation of ${ }^{14} \mathrm{CO}_{2}$ by mature brown stems of the tea plant (Camellia sinensis L.). Tea Quart. 37:140-153.

Sivapalan P (1993) Shade and green manure trees in tea-A holistic appraisal. Sri Lank. J. Tea Sci. 62:41-46.

Smith BG (1989) The effects of soil water and atmospheric vapour pressure deficit on stomatal behaviour and photosynthesis in oil palm. J. Exp. Bot. 40:647-651.

Smith BG, Burgess PJ, Carr MKV (1994) Effects of clone and irrigation on the stomatal conductance and photosynthetic rate of tea (Camellia sinensis). Exp. Agric. 30:1-16.

Smith RI, Harvey FJ, Cannell MGR (1993b) Clonal responses of tea shoot extension to temperature in Malawi. Exp. Agric. 29:47-60.

Smith BG, Stephens W, Burgess PJ, Carr MKV (1993a) 
Effects of light, temperature, irrigation and fertilizer on photosynthetic rate in tea (Camellia sinensis). Exp. Agric. 29:291-306.

Smith BG, Stephens W, Burgess PJ, Carr MKV (1993c) Responses of tea (Camellia sinensis) clones to drought: II. Stomatal conductance, photosynthesis and water potential. Aspects Appl. Biol. 34:259-267.

Squire GR (1976) Xylem water potential and yield of tea (Camellia sinensis) clones in Malawi. Exp. Agric. 12:289-297.

Squire GR (1977) Seasonal changes in photosynthesis of tea (Camellia sinensis). J. Appl. Ecol. 14:303-316.

Squire GR (1978) Stomatal behaviour of tea (Camellia sinensis) in relation to environment. J. Appl. Ecol. 15:287-301.

Squire GR (1979) Weather, physiology and seasonality of tea (Camellia sinensis) yields in Malawi. Exp. Agric. 15:321-330.

Squire GR (1985) Ten years of tea physiology. Tea 6:43-48. Squire GR (1990) The Physiology of Tropical Crop Production. CAB International, Wallingford.

Squire GR, Callander BA (1981) Tea plantations. In: Kozlowski TT (ed), Water Deficits and Plant Growth, Vol. VI, pp.471-510. Academic Press, New York.

Squire GR, Obaga SMO, Othieno CO (1993) Altitude, temperature and shoot production of tea in the Kenyan Highlands. Exp. Agric. 29:107-120.

Stephens W, Carr MKV (1989) A water stress index for tea (Camellia sinensis). Exp. Agric. 25:545-548.

Stephens W, Carr MKV (1990) Seasonal and clonal differences in shoot extension rates and numbers in tea (Camellia sinensis). Exp. Agric. 26:83-98.

Stephens W, Carr MKV (1991a) Responses of tea (Camellia sinensis) to irrigation and fertilizer. I. Yield. Exp. Agric. 27:177-191.

Stephens W, Carr MKV (1991b) Responses of tea (Camellia sinensis) to irrigation and fertilizer. II. Water use. Exp. Agric. 27:193-210.

Stephens W, Carr MKV (1993) Responses of tea (Camellia sinensis) to irrigation and fertilizer. III. Shoot extension and development. Exp. Agric. 29:323339.

Stephens W, Carr MKV (1994) Responses of tea (Camellia sinensis) to irrigation and fertilizer. IV. Shoot population density, size and mass. Exp. Agric. 30:189205.
Tanner CB, Sinclair TR (1983) Efficient water use in crop production: Research or re-search? In: Tayler HM, Jordan WR, Sinclair TR (eds), Limitations to Efficient Water Use in Crop Production, pp.1-27. American Society of Agronomy, Madison.

Tanton TW (1979) Some factors limiting yields of tea (Camellia sinensis). Exp. Agric. 15:187-192.

Tanton TW (1981) Crop growth and yields of the tea bush. Exp. Agric. 17:323-331.

Tanton TW (1982a) Environmental factors influencing the yield of tea (Camellia sinensis). II. Effects of soil temperature, day length, and dry air. Exp. Agric. 18:53-63.

Tanton TW (1982b) Environmental factors influencing the yield of tea (Camellia sinensis). I. Effects of air temperature. Exp. Agric. 18:47-52.

Tanton TW (1992) Tea crop physiology. In: Willson KC, Clifford MN (eds), Tea: Cultivation to Consumption, pp.173-199. Chapman \& Hall, London.

Wadasinghe G, Wijeratne MA (1989) Effect of potassium on water use efficiency of young tea (Camellia sinensis L.). Soil Sci. Soc. Sri Lanka 6:46-55.

Watson M (1986a) Plucking. In: Sivapalan P, Kulasegaram S, Kathiravetpillai A. (eds), Handbook on Tea, pp.7881. Tea Research Institute, Talawakelle, Sri Lanka.

Watson M (1986b) Soil and climatic requirements. In: Sivapalan P, Kulasegaram S, Kathiravetpillai A. (eds), Handbook on Tea, pp.3-5. Tea Research Institute, Talawakelle, Sri Lanka.

Wei CL, Jiang CJ, Jiang CJ, Tao HZ, Hu YH (2004) Analysis of the xanthophyll cycle component in fresh leaves of tea plant by high performance liquid chromatography and its photo-protection. J. Tea Sci. 24:60-64.

Wickramaratne MRT (1981) Genotype x environment interactions in tea (Camellia sinensis L.) and their implications in tea breeding and selection. J. Agric. Sci. (Cambridge) 96:471-478.

Wight W (1959) Nomenclature and classification of the tea plant. Nature 183:1726-1728.

Wijeratne MA (1994) Effect of climatic factors on the growth of tea (Camellia sinensis L.) in the low country wet zone of Sri Lanka. London, Wye College, University of London, $\mathrm{PhD}$ thesis.

Wijeratne MA (1996) Vulnerability of Sri Lankan tea plantations to global climate change. Water Air Soil Poll. 92:87-94. 
Wijeratne MA (2001) Shoot growth and harvesting of tea. Tea Research Institute of Sri Lanka, Talawakelle, Sri Lanka.

Wijeratne MA (2004) Effect of soil moisture deficit and temperature on dry matter accumulation in tea shoots. Sri Lank. J. Tea Sci. 69:40-50.

Wijeratne MA, Fordham R (1996) Effect of environmental factors on growth and yield of tea (Camellia sinensis L.) in the low country wet zone of Sri Lanka. Sri Lank. J. Tea Sci. 46:21-34.

Wijeratne MA, Fordham R, Anandacoomaraswamy A (1998a) Water relations of clonal tea (Camellia sinensis L.) with reference to drought resistance: I. Diurnal variations. Trop. Agric. Res. Ext. 1:1-6.

Wijeratne MA, Fordham R, Anandacoomaraswamy A (1998b) Water relations of clonal tea (Camellia sinensis L.) with reference to drought resistance: II. Effect of water stress. Trop. Agric. Res. Ext. 1:74-80. Wijeratne MA, Ratnasiri J, Premathunga EWTP (2007a)
Effect of $\mathrm{CO}_{2}$ fertilization on growth and yield of mature tea in the low country wet zone of Sri Lanka. J. Plant. Crops 31: 44-47.

Wijeratne MA, Anandacoomaraswamy A, Amarathunga MKSLD, Ratnasiri J, Basnayake BRSB, Kalra N (2007b) Assessment of impact of climate change on productivity of tea (Camellia sinensis L.) plantations in Sri Lanka. J. Nat. Sci. Found. Sri Lanka 35:119-126.

Willat ST (1971) Model of soil water use by tea. Agric. Meteorol. 8:341-351.

Willat ST (1973) Moisture use by irrigated tea in Southern Malawi. Ecol. Stud. 4:331-338.

Williams END (1971) Investigations into certain aspects of water stress in tea. In: Carr MKV, Carr S (eds) Water and the Tea Plant, pp.79-87. Tea Research Institute of East Africa, Kericho, Kenya.

Zhang J, Schurr U, Davies WJ (1987) Control of stomatal behaviour by abscisic acid which apparently originates in the roots. J. Exp. Bot. 38:1174-1181. 